Revue d'histoire de l'Amérique française

\title{
Les syndics scolaires du district de Montréal (1829-1836) : une sociographie des élus
}

\section{Christian Dessureault}

Volume 63, numéro 1, été 2009

URI : https://id.erudit.org/iderudit/039886ar

DOI : https://doi.org/10.7202/039886ar

Aller au sommaire du numéro

\section{Éditeur(s)}

Institut d'histoire de l'Amérique française

\section{ISSN}

0035-2357 (imprimé)

1492-1383 (numérique)

Découvrir la revue

\section{Citer cet article}

Dessureault, C. (2009). Les syndics scolaires du district de Montréal (1829-1836) : une sociographie des élus. Revue d'histoire de l'Amérique française, 63(1), 33-81. https://doi.org/10.7202/039886ar

\section{Résumé de l'article}

L'avènement de la démocratie scolaire au Québec remonte à 1829 lors de la mise en place des écoles de syndics. Ce nouveau système scolaire prévoit pour la première fois la mise en place d'une instance politique locale composée de représentants élus. Malgré son existence éphémère, cette institution mérite l'attention des chercheurs compte tenu de son importance dans les campagnes à la veille des Rébellions de 1837-1838 et de sa portée historique sur le développement de la démocratie scolaire. Cet article propose une sociographie des syndics élus dans la région de Montréal sous ce système scolaire entre 1829 et 1836 .

Cette sociographie s'insère dans le champ de recherche sur les élites rurales au Bas-Canada. La participation à des charges publiques est l'un des marqueurs de la condition élitaire. Les élites remplissent ainsi un rôle d'intermédiaire ou de médiateur entre la société rurale et le monde extérieur, de même que des fonctions de coordination et de direction dans leur milieu. Le mode électoral des syndics est divisé en deux phases distinctes correspondant aux lois scolaires de 1829 et de 1832 qui ont des répercussions sur le portrait social des syndics.

Dans une première phase, de 1829 à 1832, la nouvelle institution suscite l'enthousiasme d'une élite locale composée de notables (curés, seigneurs, marchands et professionnels) et de cultivateurs dont plusieurs avaient déjà acquis une expérience dans une autre instance institutionnelle importante en milieu rural : la milice. Dans la seconde phase, de 1832 à 1836, on assiste à un recul des notables et à un accroissement du poids des cultivateurs. Cette sociographie contribue à éclairer la nature composite de l'élite rurale et à montrer la prédominance des notables dans les localités dotées de bourgs importants.
Tous droits réservés @ Institut d'histoire de l'Amérique française, 2009
Ce document est protégé par la loi sur le droit d'auteur. L’utilisation des services d'Érudit (y compris la reproduction) est assujettie à sa politique d'utilisation que vous pouvez consulter en ligne.

https://apropos.erudit.org/fr/usagers/politique-dutilisation/ 


\title{
Les syndics scolaires du district de Montréal (I829-I836) : une sociographie des élus ${ }^{\mathrm{I}}$
}

\author{
CHRISTIAN DESSUREAULT \\ Département d'histoire \\ Université de Montréal
}

RÉSUMÉ • L'avènement de la démocratie scolaire au Québec remonte à 1829 lors de la mise en place des écoles de syndics. Ce nouveau système scolaire prévoit pour la première fois la mise en place d'une instance politique locale composée de représentants élus. Malgré son existence éphémère, cette institution mérite l'attention des chercheurs compte tenu de son importance dans les campagnes à la veille des Rébellions de 1837-1838 et de sa portée historique sur le développement de la démocratie scolaire. Cet article propose une sociographie des syndics élus dans la région de Montréal sous ce système scolaire entre 1829 et 1836.

Cette sociographie s'insère dans le champ de recherche sur les élites rurales au BasCanada. La participation à des charges publiques est l'un des marqueurs de la condition élitaire. Les élites remplissent ainsi un rôle d'intermédiaire ou de médiateur entre la société rurale et le monde extérieur, de même que des fonctions de coordination et de direction dans leur milieu. Le mode électoral des syndics est divisé en deux phases distinctes correspondant aux lois scolaires de 1829 et de 1832 qui ont des répercussions sur le portrait social des syndics.

Dans une première phase, de 1829 à 1832, la nouvelle institution suscite l'enthousiasme d'une élite locale composée de notables (curés, seigneurs, marchands et professionnels) et de cultivateurs dont plusieurs avaient déjà acquis une expérience dans une autre instance institutionnelle importante en milieu rural: la milice. Dans la seconde phase, de 1832 à 1836, on assiste à un recul des notables et à un accroissement du poids des cultivateurs. Cette

1. Je tiens à souligner l'apport des collègues qui ont lu avec un œil critique les premières versions de cet article, de même que celui des évaluateurs externes et des membres du comité de la revue. Nous avons réalisé les cartes de cet article en utilisant un modèle de base conçu dans le cadre d'un projet de recherche sur la milice mené conjointement avec Roch Legault du Collège militaire royal de Kingston et subventionné par le CRSH-Canada. 
sociographie contribue à éclairer la nature composite de l'élite rurale et à montrer la prédominance des notables dans les localités dotées de bourgs importants.

ABSTRACT • School governance in Quebec gained a measure of democracy in 1829, with the creation of trustee-managed schools. The new system provided for the creation of an elected board, a first in the province. Despite its short lifespan, this system deserves attention considering the important role it played in the period preceding the Rebellions and its impact on the development of a democratic system of school governance. This article will provide a picture of the social backgrounds of the trustees elected in the Montreal region between 1829 and 1836.

This sociographical study informs the larger question of rural elites in Lower Canada. Election to public office was a clear indicator of a higher position within a community hierarchy. Elite individuals served as both agents of communication between a rural communities and the outside world and as leaders within their own community. The election of trustees was divided into two different phases, defined by the laws of 1829 and 1832. Both of these laws had a noticeable impact on the social profile of the trustees.

During the first phase, which lasted from 1829 to 1832, the new system attracted the interest of a local elite composed of notables (clergy, seigneurs, merchants and professionals) and farmers, many of whom already had experience with another important rural institution: the militia. The second phase, which lasted from 1832 to 1836, brought about an increase in the number of farmers and a reduction in the number of notables. This sociographical study contributes to an understanding of the composition of rural elites while underscoring the importance of notables in areas where larger towns were located.

\section{T 'avènement de la démocratie scolaire au Québec remonte à 1829 lors Lde la mise en place des écoles de syndics². Ce système scolaire prévoit, pour une première fois, l'établissement d'une instance politique locale composée de représentants élus auxquels le gouvernement colonial confère le pouvoir d'administrer des écoles élémentaires publiques dans les campagnes du Bas-Canada ${ }^{3}$. Cette institution connaît une existence éphémère puisqu'elle s'éteint dès 1836 lorsque le Conseil législatif refuse,}

2. Jean-Pierre Proulx, «L'évolution de la législation relative au système électoral scolaire québécois (1829-1989)", Historical Studies in Education/Revue d'histoire de l'éducation, 10,1-2 (1998): 20.

3. Les populations locales ne disposaient pas de pouvoir réel sous le système de l'Institution royale, car leur rôle se limitait à demander l'établissement d'une école au gouverneur. Puis, la loi des écoles de fabrique a ouvert la porte à l'intervention des communautés locales dans le domaine scolaire. Cependant, la principale fonction de la fabrique demeurait l'administration des biens temporels de la paroisse et non le domaine scolaire. Cette institution était administrée par un conseil comprenant le curé et des laïques, nommés marguilliers, dont le mode de sélection variait d'une paroisse à l'autre. Le pouvoir des communautés locales sur le fonctionnement de cette institution demeurait donc lié au mode plus ou moins démocratique de sélection des marguilliers et à la capacité du curé d'influencer les individus nommés ou élus au conseil de la fabrique. 
pour des motifs financiers et politiques, d'entériner un projet de loi qui aurait permis le maintien des écoles de syndics ${ }^{4}$. Ces écoles de syndics ont eu une portée historique considérable et elles méritent l'attention des chercheurs. Elles ont influencé l'évolution subséquente du système scolaire ${ }^{5}$ et elles ont occupé une place importante dans les débats idéologiques et les conflits politiques à la veille des Rébellions de 1837-1838. Cette étude se veut une modeste contribution dans une enquête plus large sur la genèse de la démocratie scolaire ${ }^{7}$. Nous voulons effectuer dans cet article une sociographie des syndics scolaires élus entre 1829 et 1836.

Cette sociographie devrait contribuer à la connaissance du système des écoles de syndics. À ce sujet, nous adhérons à la conception selon laquelle une institution se définit autant en étudiant les hommes ou les femmes qui l'habitent qu'en examinant ses règles et ses statuts officiels ${ }^{8}$. Cependant, l'examen des règles d'une institution, de ses cadres légaux, demeure un préalable à l'étude de sa composition sociale. Ceux-ci fixent en quelque sorte des balises concernant l'accès à des fonctions au sein d'une institution. Ces règles délimitent aussi le rôle des acteurs.

Selon Fernand Ouellet, la loi des écoles élémentaires de 1829 s'insère dans une stratégie du Parti patriote visant à assurer la conquête du pouvoir aux classes moyennes canadiennes-françaises par la généralisation du principe électif. «Le système électif proposé par les réformistes limite le droit de vote aux propriétaires et son objectif pratique est d'étendre autant que possible le pouvoir des élites laïques liées avec le parti ${ }^{9}$.» Cette hypothèse n'est toutefois étayée par aucune étude sur la composition sociale des syndics scolaires élus entre 1829 et 1836 . De plus, cette notion de classes moyennes demeure floue sur le plan théorique et tout aussi vague en termes de contenu empirique. La composition des élites rurales reste d'ailleurs un vaste sujet à explorer.

4. Louis-Philippe Audet, Le système scolaire de la Province de Québec: les écoles élémentaires dans le Bas-Canada 1800-1836 (Québec, Les Éditions de l’Érable, 1955), V: 275-281.

5. Sur cette question, voir Andrée Dufour, Tous à l'école. État, communautés rurales et scolarisation au Québec de 1826 à 1859 (Montréal, Hurtubise HMH, coll. "Cahiers du Québec», 1996), 255-256.

6. Bruce Curtis, «State of the Nation or Community of Spirit? Schooling for Civic and EthnicReligious Nationalism in Insurrectionnary Canada », History Education Quarterly, 43,3 (Fall 2003): 325-349.

7. Cette enquête sur la genèse de la démocratie scolaire est menée par Jean-Pierre Proulx de la Faculté des sciences de l'Éducation de l'Université de Montréal et nous avons accepté avec plaisir de collaborer avec lui en effectuant cette sociographie des syndics scolaires.

8. Philippe Minard, «Faire l'histoire sociale des institutions: démarches et enjeux», Bulletin de la Société d'histoire moderne et contemporaine, 3,4 (2000): 119-123.

9. Fernand Ouellet, Le Bas-Canada 1791-1840. Changements structuraux et crise (Ottawa, Éditions de l'Université d'Ottawa, 1980), 332. 
Cette sociographie des syndics scolaires s'insère dans le nouveau champ de recherche sur les élites rurales au Bas-Canada. La participation à des charges institutionnelles est l'un des marqueurs de la condition élitaire dans les campagnes. Les élites rurales exercent un rôle d'intermédiaire ou de médiateur entre la société rurale et le monde extérieur. Plusieurs travaux ont démontré la pertinence d'étudier les institutions locales et les élites institutionnelles ${ }^{10}$. Les premières recherches pour la région de Montréal ont porté sur la composition sociale de certaines institutions comme la fabrique, la milice et la justice de paix $^{11}$. Plus récemment, les travaux de Jean-René Thuot ont démontré la nécessité d'élargir ce type d'enquête à l'ensemble des institutions et de leurs acteurs à l'échelle d'une paroisse ou d'une région ${ }^{12}$. Cette approche a permis de mieux saisir la relation entre la participation à des instances institutionnelles d'importance variable et la condition élitaire d'un individu ou d'un réseau d'individus soudés par des liens familiaux. Ces travaux ont aussi insisté sur le statut élitaire de certains paysans très actifs dans les réseaux institutionnels locaux. Ces derniers assumaient dans leur milieu des rôles de coordination, de pouvoir et de représentation.

Cette inclusion de cultivateurs au sein de l'élite rurale ne fait toutefois pas l'unanimité parmi les chercheurs qui ont écrit sur le monde rural québécois dans la première moitié du $\mathrm{xIx}^{\mathrm{e}}$ siècle. Les travaux plus anciens de Fernand Ouellet sur les insurrections de $1837-1838^{13}$ et de Richard

10. Parmi les travaux pionniers qui ont abordé la question de l'évolution des institutions locales dans le Québec du milieu du XIX ${ }^{e}$ siècle, voir John I. Little, State and Society in Transition. The Politics of Institutionnal Reform in the Eastern Townships 1838-1852 (Montreal, McGill-Queen's University Press, 1997).

11. Christian Dessureault et Christine Hudon, "Conflits sociaux et élites au Bas-Canada: le clergé, les notables, la paysannerie et le contrôle de la fabrique». The Canadian Historical Review, 80,3 (septembre 1999) : 413-439; Christian Dessureault et Roch Legault, «Évolution organisationnelle et sociale de la milice sédentaire canadienne : le cas du bataillon de Saint-Hyacinthe, 18081830 ». Journal of Canadian Historical Association/Revue de la Société historique du Canada, 7 (1997): 87-112; Donald Fyson, Magistrates, Police and People. Everyday Criminal Justice in Quebec and Lower Canada, 1764-1837 (Toronto, The Osgoode Society for Canadian Legal History, University of Toronto Press, 2006), $467 \mathrm{p}$

12. Jean-René Thuot, "Élites locales, institutions et fonctions publiques dans la paroisse de Saint-Roch-de-l'Achigan, de 1810 à 1840 ", Revue d'histoire de l'Amérique française, 57,2 (automne 2003): 173-208; Jean-René Thuot, D’une assise locale à un réseau régional: élites et institutions dans Lanaudière (1825-1865), thèse de doctorat (Histoire), Université de Montréal, 2008.

13. Cet historien constate la présence d'un leadership paysan lors du mouvement insurrectionnel, mais cette facette constitue selon lui un indice de la carence de la petite bourgeoisie à assumer son rôle dans l'action. F. Ouellet, «Les insurrections de 1837-38: un phénomène social», Histoire sociale/Social History, 2 (novembre 1968): 54-82. 
Chabot sur les conflits autour de la fabrique ${ }^{14}$, quoique conscients des inégalités parmi les cultivateurs, présentent des paysans manipulés par des forces extérieures tantôt par les curés, tantôt par la petite bourgeoisie. Les travaux plus récents d'Allan Greer sur la dynamique des Rébellions de 1837-1838 en milieu rural ${ }^{15}$ et de Wendie Nelson sur la résistance rurale devant l'imposition d'un système scolaire local au milieu du $\mathrm{XIX}^{\mathrm{e}}$ siècle $^{16}$ réfutent cette thèse d'une manipulation de la société paysanne par des élites externes. Cependant, cette société paysanne agit alors comme un tout organique, relativement homogène, pour la défense de son autonomie et de ses intérêts collectifs. Cette recherche sur les syndics scolaires ne prétend pas apporter une réponse globale à ce débat sur les élites rurales, ni sur la place occupée par les cultivateurs au sein de cette élite et sur leurs rapports avec les autres factions de l'élite rurale. Cependant, elle apporte une contribution additionnelle à la conception d'une élite rurale socialement composite. L'étude du recrutement des élites institutionnelles demeure aussi une piste nécessaire à creuser, d'une part, pour mieux définir à une échelle plus large les variations dans l'espace du profil social du personnel institutionnel et, d'autre part, pour évaluer l'importance relative des différentes institutions. Le recrutement au sein d'une institution est souvent lié à sa fonction, à ses règles et à son évolution historique. C'est dans cette perspective que nous examinerons le profil social des syndics scolaires.

\section{LA GENÈSE DES ÉCOLES DE SYNDICS: UN BREF RAPPEL HISTORIQUE}

Au Québec, le premier système public d'écoles élémentaires, l'Institution royale, a été créé en $1801^{17}$. Boudé par le clergé catholique, ce premier système scolaire contrôlé par une corporation placée sous l'autorité directe du gouverneur connaît un succès mitigé au sein de la population rurale francophone et catholique. À partir de 1814, la Chambre d'assemblée du Bas-Canada présente divers projets de loi visant à implanter un nouveau système d'écoles élémentaires mieux adapté aux besoins de la

14. Richard Chabot, Le curé de campagne et la contestation locale au Québec (de 1791 aux troubles de 1837-1838) (Montréal, Hurtubise HMH, 1975), chap. 2, 75-98.

15. Allan Greer, Habitants et patriotes. La Rébellion de 1837 dans les campagnes du Bas-Canada (Montréal, Éditions du Boréal, 1997).

16. Wendie Nelson, "Rage Against the Dying of the Light": Interpreting the Guerre des Éteignoirs", The Canadian Historical Review, 81,4 (December 2000) : 551-581.

17. Pour un historique plus détaillé des premiers systèmes publics d'écoles élémentaires au Bas-Canada, voir A. Dufour, op. cit., chap. 1: Avènement des écoles de syndics, 35-55. Voir aussi L.-P. Audet, op. cit. 
majorité de la population ${ }^{18}$. Ces premiers projets achoppent. La tension politique entre le pouvoir colonial et la Chambre d'assemblée ne contribue pas à favoriser leur concrétisation ${ }^{19}$.

En 1824, la Chambre d'assemblée, le Conseil législatif et le gouverneur Dalhousie établissent un premier système d'écoles élémentaires administrées localement: les écoles de fabrique ${ }^{20}$. La fabrique est une institution locale dédiée à la gestion des biens matériels de l'Église dans une paroisse. Néanmoins, les communautés locales ont fréquemment utilisé cette institution pour intervenir dans d'autres sphères de leur vie collective ${ }^{21}$. La fabrique remplit avec plus ou moins de succès sa nouvelle mission dans le domaine scolaire ${ }^{22}$. De 1824 à 1828 , on constate pour l'ensemble du Bas-Canada la création d'à peine une cinquantaine d'écoles de fabrique. Le faible intérêt des curés de campagne pour les écoles élémentaires ${ }^{23}$ ainsi que les conflits sociopolitiques autour du contrôle de la fabrique ${ }^{24}$ ont sans doute contribué à cet échec.

Dès 1826, le gouverneur Dalhousie invite la Chambre d'assemblée et le Conseil législatif à prendre de nouvelles mesures dans le secteur de l'éducation. En février 1827, le député Blanchet note l'urgence pour le gouvernement de soutenir financièrement l'établissement d'écoles élémentaires ${ }^{25}$. Le même jour, les députés votent $£ 10000$ pour l'encouragement de l'éducation et ils confient à un comité le soin de rédiger un «bill» pour l'encouragement de l'éducation ${ }^{26}$. Cependant, cette initiative tourne court en raison de la décision du gouverneur Dalhousie de dissoudre le Parlement et de convoquer de nouvelles élections ${ }^{27}$. Même si l'éducation n'est pas

18. Sur ces divers projets de loi, voir L.-P. Audet, op. cit., chap. VI : La Chambre et l'éducation de 1801 à $1824,48-64$.

19. Sur les tensions politiques permanentes au Bas-Canada durant cette période, voir. F. Ouellet, op. cit., chap. VIII-IX-X: La paralysie des institutions politiques, 291-420.

20. Acte pour faciliter l'établissement et la dotation d'Écoles élémentaires dans les Paroisses de cette Province, Lois de la province du Bas-Canada, 4, Geo. IV, ch. 3, 9 mars 1824.

21. A. Greer, «L'habitant, la paroisse rurale et la politique locale au $18 \mathrm{e}$ siècle», Société canadienne d'histoire de l'Église catholique, 47 (1980): 19-33.

22. R. Chabot, op. cit., chapitre 1, 45-73.

23. Ibid.

24. C. Dessureault et C. Hudon, op. cit.

25. Reproduction d'un débat sur les écoles élémentaires du 24 février 1827, La Minerve, le $1^{\mathrm{er}}$ mars 1827.

26. La Minerve, le 6 mars 1827.

27. Un article publié le 26 mars dans La Minerve répertorie trois «bills» concernant l'éducation, un «bill» concernant la milice et un «bill» concernant la fabrique parmi les «bills» arrêtés dans leur progression et mettant en péril l'état de la Province par la dissolution précipitée de la Chambre d'assemblée par le gouverneur Dalhousie. La Minerve, le 26 mars 1827. 
l'objet du différend entre ce gouverneur et les députés du Parti patriote, cette crise politique retarde l'action du gouvernement dans ce domaine. Cependant, dès le début de l'année 1828, la nomination du nouveau gouverneur Kempt ouvre une courte période d'accalmie politique propice à la concrétisation de projets politiques chers au Parti patriote. Dans le domaine de l'éducation, une loi est adoptée le 24 mars 1829 prévoyant l'établissement d'un nouveau système d'écoles élémentaires: les écoles de syndics ${ }^{28}$.

La loi des écoles de syndics de 1829 crée un nouveau système public d'écoles élémentaires financées à la fois par les parents des élèves, par les communautés locales et par le gouvernement colonial ${ }^{29}$. Le gouvernement maintient par ailleurs les anciens réseaux de l'Institution royale et des écoles de fabrique. La colonie compte aussi plusieurs écoles élémentaires privées. Les communautés locales sont désormais impliquées dans le fonctionnement d'un réseau scolaire.

La gestion des écoles de syndics est effectivement confiée à des hommes élus par l'ensemble des propriétaires d'une localité : tantôt à l'échelle d'une paroisse, tantôt à l'échelle d'une seigneurie, tantôt à l'échelle d'un canton. Le gouvernement conserve néanmoins la supervision du réseau scolaire. Les élus locaux doivent rendre des comptes à la Chambre d'assemblée et au gouverneur de leur administration et surtout des dépenses effectuées à partir des fonds alloués par l'État pour la construction et le fonctionnement des écoles.

De plus, à partir de 1831, le gouvernement nomme 19 visiteurs des écoles pour l'ensemble du Bas-Canada ${ }^{30}$. Ces derniers ont la responsabilité de surveiller la qualité du fonctionnement académique des écoles et la rigueur de la gestion financière des syndics dans un territoire couvrant, selon le cas, d’un à trois comtés ${ }^{31}$. Cette charge est généralement confiée à un député élu dans l'un des comtés du «district scolaire». Par ailleurs,

28. Acte pour encourager l'Éducation élémentaire, Lois de la province du Bas-Canada, 9, Geo. IV, ch. 46, 14 mars 1829.

29. Sur les contributions respectives des communautés locales, de l'État et des parents, voir A. Dufour, op. cit.

30. Acte pour pourvoir ultérieurement à l'encouragement de l'Éducation en cette Province et pour amender deux certains actes y mentionnés, Lois de la province du Bas-Canada, 1, Guill. IV, ch. 7, 31 mars 1831.

31. Dans la région de Montréal, les sept «districts» scolaires de ces visiteurs sont: 1. Les comtés de Richelieu, Rouville et Saint-Hyacinthe; 2. Les comtés de Verchères et Chambly; 3. Les comtés de Laprairie et de l'Acadie; 4. Le comté de Beauharnois; 5. Le comté de Vaudreuil ; 6. Les comtés de Deux-Montagnes, Terrebonne et Lachenaye; 7. Les comtés de L'Assomption et Berthier. Pour la liste complète et la description des districts scolaires du Bas-Canada, voir JCABC, 1831, Appendice BB, Rapport du Comité sur l'éducation. 
ces visiteurs peuvent compter sur l'assistance d'un autre député, d'un juge de paix ou d'un officier de milice ainsi que d'un curé ou d'un pasteur, pour effectuer leur inspection des écoles.

Le démarrage du nouveau système scolaire entraîne rapidement la multiplication du nombre d'écoles élémentaires et du nombre d'élèves ${ }^{32}$. Cette expansion rapide suscite des défis importants pour les communautés locales et pour le gouvernement colonial. Devant l'explosion du nombre d'écoles, les syndics locaux ne réussissent pas toujours à recruter des maîtres ou des maîtresses compétents pour instruire adéquatement les enfants $^{33}$. Par ailleurs, on assiste à une hausse considérable des dépenses du gouvernement en éducation. Cette croissance soudaine des coûts suscite des divisions et des résistances au sein du gouvernement entre d'une part, le Conseil exécutif et le Conseil législatif et, d'autre part, la Chambre d'assemblée. Ces divisions sont aussi présentes au sein de la Chambre d'assemblée où la majorité des députés demeurent partisans des écoles de syndics. En 1836, dans un contexte de détérioration majeure du climat politique, le Conseil législatif refuse d'adopter un nouveau projet de loi de la Chambre d'assemblée dans le domaine scolaire. Ce refus marque alors la fin du système des écoles de syndics compte tenu de l'expiration de la dernière loi scolaire en vigueur, le $1^{\mathrm{er}}$ mai 1836.

\section{LE TERRAIN D'ENQUÊTE}

Cette étude des syndics scolaires est circonscrite à la région de Montréal de 1829 à 1836. Le choix des limites temporelles est simple. Cette recherche couvre la durée complète des écoles de syndics. Cette période des écoles de syndics se divise en deux phases correspondant chacune à une loi et à un mode électoral des syndics.

La loi scolaire de 1829 marque le début du nouveau système scolaire. Durant une première phase qui s'étend de 1829 jusqu'en 1832 , la loi pré-

32. Pour des données sur cette croissance, voir le tableau publié dans A. Dufour, op. cit., 42.

33. Cette critique des écoles de syndics se fonde, dans la plupart des travaux, sur les commentaires d'opposants contemporains à ce système scolaire. Nous ne disposons malheureusement pas de données fiables sur la qualification du personnel des écoles de syndics. L'explosion du nombre d'écoles élémentaires au Bas-Canada entre 1829 et 1836 a certainement posé un défi important pour le recrutement de maîtres et de maitresses capables de remplir convenablement cette tâche difficile. L'enquête menée par le Comité d'éducation de la Chambre d'assemblée en novembre 1835 aborde aussi cette question et dresse un bilan plutôt nuancé. Parmi les députés qui ont alors été interrogés par les membres du comité, une majorité sans doute favorable aux écoles de syndics affirma que «les maîtres et les maîtresses étaient qualifiés ou même très qualifiés aux yeux de la loi tandis qu'une minorité reconnut la présence dans leur comté d'un certain nombre de maîtres peu ou pas compétents. Voir A. Dufour, «Les institutrices du Bas-Canada: incompétentes et inexpérimentées?», RHAF, 51,4 (printemps 1998): 539. 
voit l'élection de cinq syndics dans chacune des localités rurales (cantons, paroisses ou seigneuries) $)^{34}$. L'élection des syndics s'effectue lors d'une assemblée annuelle "des tenanciers de telle Paroisse, Seigneurie ou Township " qui est présidée par le principal ou le plus ancien officier de milice de la localité ou par un juge de paix. Cette loi limite ainsi le droit de vote aux propriétaires fonciers ${ }^{35}$. Les candidats désireux de remplir la charge de syndics doivent aussi être propriétaires dans leur localité. Dès 1830, un amendement crée toutefois une exception pour les curés et pour les pasteurs protestants qui n'auront plus à posséder de biens fonciers dans une localité pour y détenir une charge de syndic scolaire ${ }^{36}$.

Une seconde phase s'amorce en 1832 lorsque l'adoption d'une nouvelle loi modifie le fonctionnement du système des syndics ${ }^{37}$. La gestion des écoles est alors confiée à trois syndics élus pour un mandat de deux ans à l'échelle d'un arrondissement. Ces arrondissements couvrent des secteurs précis d'une localité se limitant généralement à un ou deux rangs. Les bourgs constituent dans certaines localités des arrondissements scolaires. La loi de 1832 précise le nombre des arrondissements dans chacun des comtés et chaque arrondissement est «délimité et approuvé par les visiteurs d'écoles sous l'autorité d'un Acte passé dans la dernière session du parlement provincial ${ }^{38}$ ». Les arrondissements disposent d'une école élémentaire mixte pour les filles et les garçons, ou de deux écoles élémentaires distinctes pour les garçons et pour les filles. La loi de 1832 accorde le droit de vote à tous les chefs de famille ayant le droit de voter lors des élections pour la Chambre d'assemblée. Les syndics scolaires sont ainsi choisis parmi les chefs de famille propriétaires d'un arrondissement lors d'une assemblée présidée par un juge de paix ou par l'officier de milice le plus haut en grade dans la localité.

La délimitation du terrain d'enquête est un peu plus complexe. Nous avons voulu restreindre cette étude des syndics scolaires à la région de Montréal, car ce type de recherche, menée à l'échelle du Bas-Canada,

34. Acte pour encourager l'Éducation élémentaire, Lois de la province du Bas-Canada, 9, Geo. IV, ch. 46, 14 mars 1829.

35. La loi de 1829 ne fournit aucune précision sur l'âge ou sur le sexe des électeurs. Les femmes propriétaires avaient donc théoriquement le droit de vote, mais nous n’avons retrouvé aucune information sur leur présence dans les assemblées locales de tenanciers.

36. Acte pour amender un Acte passé dans la neuvième année du Règne de Sa Majesté, à l'égard de l'Éducation élémentaire, et pour pourvoir ultérieurement à l'Instruction de la Jeunesse, Loi 10-11, Geo. IV, ch. 14, 26 mars 1830.

37. Acte pour rappeler certains Actes y mentionnés et pour encourager ultérieurement les Écoles élémentaires dans les Campagnes de cette Province, Loi 2, Guill. IV, ch. 26, 25 février 1832.

38. L.-P. Audet, op. cit., 184. 
constituait une tâche considérable qui n'était pas nécessaire pour valider les résultats de l'enquête. De plus, nous possédions déjà des banques de données pour effectuer le repérage et le suivi des individus ayant occupé des charges de syndics scolaires dans la région de Montréal.

Nous sommes conscients que la notion de région peut sembler, au tournant des années 1830, un anachronisme malgré l'existence, depuis l'époque de la Nouvelle-France, d'un district administratif de Montréal s'étendant de Berthier et Sorel jusqu'aux frontières actuelles de l'Ontario et des États-Unis. Les limites territoriales du district de Montréal varient toutefois dans le temps au gré de l'extension du peuplement et, selon les périodes, ce district inclut ou exclut des cantons et des seigneuries situés dans les régions actuelles de l'Estrie et de l'Outaouais. Par ailleurs, les écoles de syndics représentent une institution intimement liée à l'État colonial et à la Chambre d'assemblée. La gestion des écoles est confiée à des élus locaux, mais ceux-ci doivent rendre des comptes à des représentants de l'État. Depuis 1831, le gouvernement délègue à des visiteurs nommés à l'échelle d'un à trois comtés la responsabilité d'inspecter les écoles et de valider le travail effectué par les syndics. Or, c'est un député qui remplit cette fonction d'intermédiaire entre les écoles de syndics et l'État. Nous avons donc tenu compte de cette dimension à la fois administrative et politique pour fixer les limites de la région étudiée. Pour cette étude, la région de Montréal comprend les paroisses rurales de l'île de Montréal et toutes les localités de la partie méridionale du Bas-Canada comprises à l'intérieur d'un nombre précis de comtés. Les limites territoriales de ces comtés ont été définies par la réforme électorale de $1829^{39}$. Cette carte électorale demeure en vigueur jusqu'à la fin de notre période. Ces circonscriptions électorales de la région de Montréal, en plus des paroisses rurales de l'île de Montréal, sont Berthier, L'Assomption, Lachenaye, Terrebonne, Deux-Montagnes, Vaudreuil, Richelieu, Verchères, Saint-Hyacinthe, Rouville, Chambly, Laprairie, L'Acadie et Châteauguay. Ces comtés correspondent aussi à des districts de recensement en 1831.

Les unités territoriales de base servant à l'étude sociale des syndics sont les subdivisions territoriales à l'intérieur de ces comtés lors du recensement de 1831. Ces subdivisions correspondent le plus souvent à des paroisses, mais aussi à des cantons ou à des seigneuries. Certains bourgs ou villages constituent également des subdivisions lors du recensement de 1831. Mais, 


\section{Carte I}

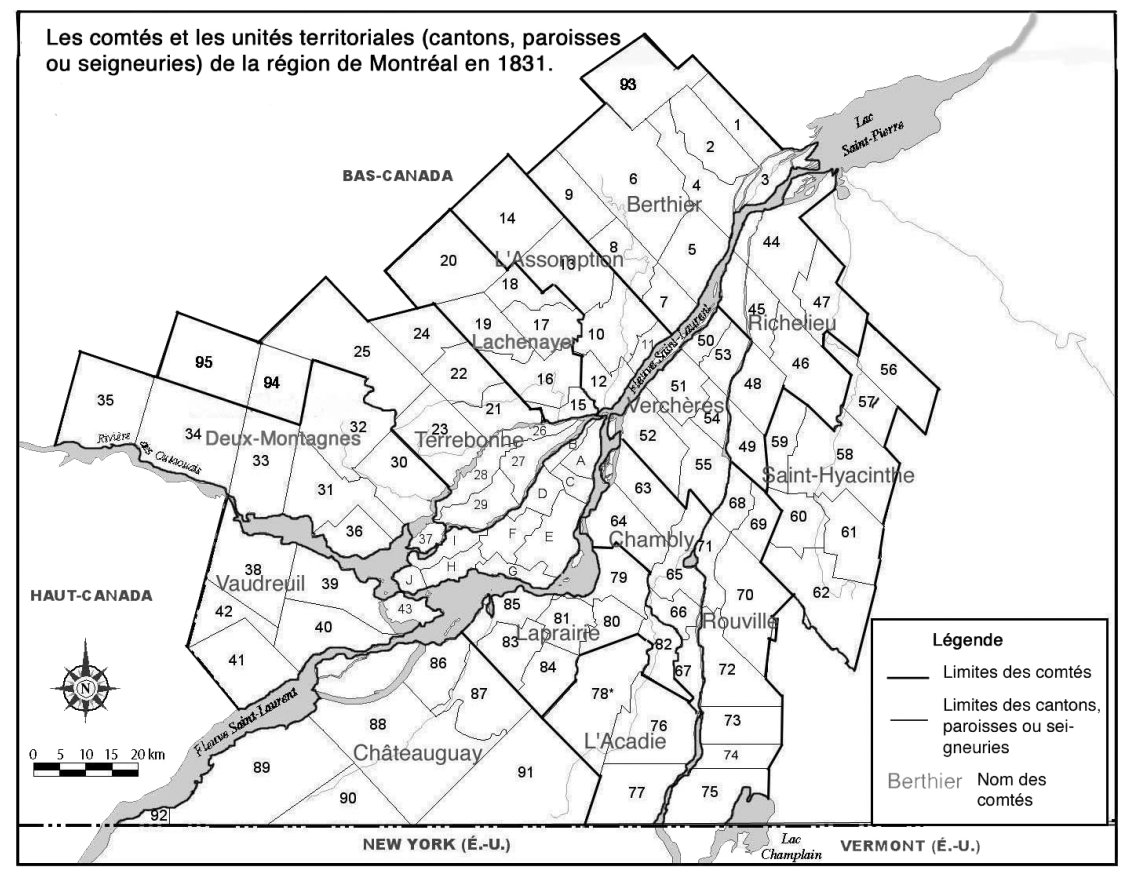

pour cette étude, nous avons intégré les bourgs aux cantons, paroisses ou seigneuries où ils étaient situés. De 1831 à 1836, nous avons constaté la création de nouvelles paroisses. Cependant, la plupart de ces paroisses constituaient déjà, lors du recensement de 1831, des subdivisions à l'intérieur des comtés ${ }^{40}$. Pour les autres, peu nombreuses, nous n'avons pas retrouvé de syndics scolaires ${ }^{41}$. Notre terrain d'enquête se limite donc aux paroisses, aux seigneuries et aux cantons des comtés retenus où les recenseurs ont relevé la présence d'une population en 1831 (carte 1).

40. Ainsi, les paroisses de Saint-Simon (ouverture officielle des registres en 1832), de SaintAndré d'Argenteuil (1833), de Saint-Édouard-de-Napierville (1833), de Saint-Isidore (1833), de Saint-Jérôme (1834) et de Saint-Lin (1835) constituent déjà des subdivisions spécifiques lors du recensement de 1831 .

41. C'est le cas de la paroisse de Sainte-Rosalie constituée en 1833 à partir d'une division de la paroisse de Saint-Hyacinthe et de la paroisse de Saint-Ignace-du-Côteau-du-Lac constituée aussi en 1833 à partir d'une division de la paroisse de Saint-Joseph-de-Soulanges. Par ailleurs, les paroisses de Saint-Édouard-de-Napierville et de Saint-Georges-de-Henryville, dont les registres débutent en 1833, couvrent ensemble la subdivision paroissiale identifiée sous le nom de Saint-Édouard lors du recensement de 1831. En 1831, le recenseur emploie toutefois pour ce même territoire peuplé de Francophones catholiques et d'Anglophones protestants deux types de subdivisions en identifiant, à l'intérieur de la paroisse de Saint-Édouard, les seigneuries de St-George, de St-James, de Thwaite et le township de Sherrington. Dans notre étude, nous regroupons l'ensemble de ce territoire dans une seule unité territoriale ou subdivision sous le nom de Saint-Édouard. 


\section{LES SOURCES PRINCIPALES DE L'ENQUÊTE}

Nous disposons de 377 comptes rendus d'élections scolaires entre 1829 et 1836. De ce nombre, 188 comptes rendus se rapportent à des élections générales ou partielles tenues à l'échelle des localités en vertu de la loi de $1829^{42}$, et 189 comptes rendus concernent des élections tenues à l'échelle des arrondissements, en vertu de la loi scolaire de $1832^{43}$.

Les comptes rendus des élections qui ont eu lieu durant la première phase des écoles de syndics proviennent de deux sources: les minutes des notaires du district de Montréal ${ }^{44}$ et le Book of School Trustees for 1830 and $1831^{45}$. Le Book of School Trustees comprend une nombre considérable de comptes rendus d'élections scolaires ayant eu lieu dans des cantons, des paroisses ou des seigneuries du Bas-Canada entre 1829 et 1832 . Nous pouvons y retrouver pour chaque localité les noms des cinq syndics élus. Les statuts ou les professions de ces syndics sont rarement mentionnés sauf en ce qui a trait à la présence des membres des clergés catholique ou protestant. Pour la région de Montréal, nous avons retrouvé dans le Book of School Trustees 162 comptes rendus d'élections scolaires générales.

Les minutes notariales constituent une source complémentaire pour cette première phase des écoles de syndics. Nous disposons pour l'ensemble de la région de Montréal de 50 actes notariés dressant des procèsverbaux d'élections tenues en vertu de la loi de 1829. De ces 50 élections, 24 ont aussi été relevées dans le Book of School Trustees. Cette source permet donc d'identifier 26 nouvelles élections dont 21 élections générales et 5 partielles visant à remplacer un syndic démissionnaire ou décédé ${ }^{46}$. Nous disposons donc pour la première phase des écoles de syndics de 188 comptes rendus électoraux dont 183 concernent des élections générales et 5 des élections partielles.

Par ailleurs, les greffes des notaires constituent une source incontournable pour étudier les élections de la seconde phase des écoles de syndics de 1832 à 1836 . Cependant, cette source ne permet de retracer qu'une

42. Le nombre annuel de ces élections à l'échelle des localités (paroisses, seigneuries ou townships) est de 19 en 1829, de 77 en 1830 , de 88 en 1831 et de 4 en 1832.

43. Le nombre annuel de ces élections à l'échelle des arrondissements est de 95 en 1832, de 1 en 1833 , de 90 en 1834 et de 3 en 1835.

44. BAnQ, minutes des notaires des districts judiciaires de Montréal, de Berthier, de Joliette, de Saint-Hyacinthe, de Saint-Jean, de Saint-Jérôme, de Sorel et de Valleyfield (CN601 à CN606 inclus). Le repérage et le dépouillement de comptes rendus électoraux dans les minutes notariales ont été en grande effectués par Jean-Pierre Proulx.

45. BAC, RG4, B30, Book of School Trustees for 1830 et 1831, dossiers relatifs à l'éducation.

46. Nous incluons parmi ces élections partielles l'élection de deux syndics d'une même côte chevauchant les paroisses de Pointe-Claire et de Sainte-Geneviève. 
faible proportion des syndics élus même si le dépôt chez un notaire des rapports des élections syndics était une obligation légale ${ }^{47}$. Les 189 procèsverbaux d'élections scolaires tenues à l'échelle des arrondissements proviennent essentiellement de cette source ${ }^{48}$. Ces comptes rendus fournissent le nom de syndics et, selon les actes, des mentions plus ou moins régulières de leur statut ou de leur profession. Ces actes permettent quelquefois de vérifier la capacité de signer des syndics. De plus, les notaires ont identifié les présidents des élections en notant la fonction civile qui leur conférait ce privilège: officier de milice ou juge de paix. Certains notaires identifient une partie des tenanciers présents lors de l'élection.

\section{LA REPRÉSENTATIVITÉ SPATIALE DES ÉLECTIONS SCOLAIRES}

Dans une première phase des écoles de syndics, les élections ont été tenues à l'échelle des localités : cantons, paroisses et seigneuries. Dans la plupart des cas, ces localités correspondent aux subdivisions territoriales employées, à l'intérieur des comtés, lors du recensement de 1831. Nous pouvons donc suivre la répartition dans l'espace des élections tenues durant cette première phase des écoles de syndics, du moins pour les élections ayant laissé des traces dans les sources (carte 2).

Nous pouvons d'abord identifier certaines localités où des élections scolaires ont été organisées, de manière distincte, sur une partie seulement de leur territoire. Ces exceptions sont relativement peu nombreuses. Nous devons d'abord noter le cas de la paroisse de Sorel ( $n^{\circ} 44$ sur la carte) dans le comté de Richelieu où des élections séparées ont eu lieu pour la paroisse et pour le bourg de William Henry ${ }^{49}$. Dans le comté de Verchères, la paroisse de Varennes ( $n^{\circ} 52$ ) a également été découpée en deux secteurs pour les élections scolaires, soit l'île Sainte-Thérèse et le Grand Côteau.

La paroisse de Sainte-Élizabeth ( $n^{\circ}$ 6) dans le comté de Berthier constitue un autre exemple de la complexité du découpage des espaces institutionnels où interfèrent les divisions paroissiales et seigneuriales. Nous y avons relevé deux élections à l'échelle de la paroisse, deux autres à l'échelle de la seigneurie de Dailleboust couvrant environ la moitié de cette paroisse

47. D’ailleurs, dans la première phase des écoles de syndics, nous avons constaté que de nombreux comptes rendus électoraux recensés dans le Book of School Trustees n’ont pas été déposés chez les notaires ou du moins n’ont pas été conservés dans leur minutier.

48. Le repérage et le dépouillement initial de ces comptes rendus électoraux ont été effectués par Jean-Pierre Proulx.

49. La division est toutefois davantage ethnoculturelle et religieuse que territoriale : les syndics élus pour le William Henry comptent essentiellement des résidants anglo-protestants tandis qu'une partie des syndics de la paroisse de Sorel sont des résidants franco-catholiques du bourg. 


\section{Carte 2}

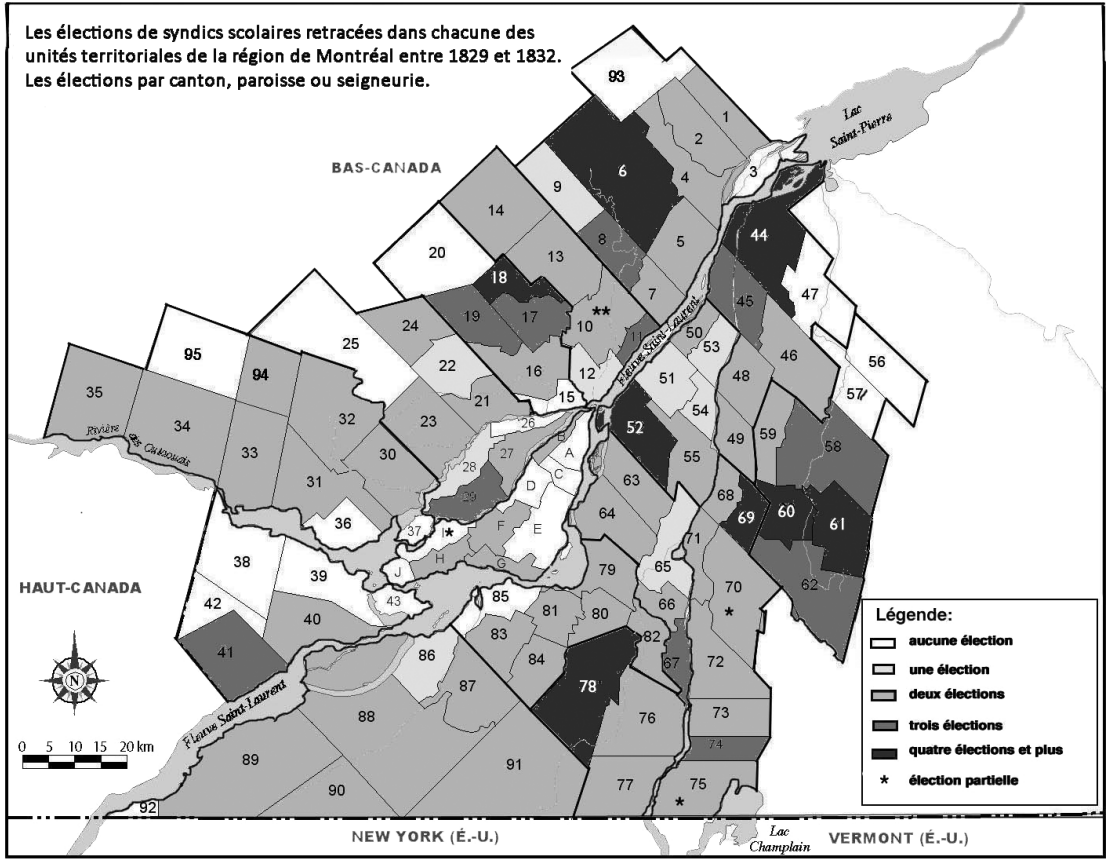

et une dernière élection à l'échelle de la seigneurie de Ramesay couvrant l'autre moitié de cette paroisse.

Cet enchevêtrement des découpages est également présent dans le comté de l'Acadie. Nous y avons intégré dans une même unité territoriale les élections tenues dans la paroisse de Saint-Édouard ( $\left.\mathrm{n}^{\circ} 78\right)$, la seigneurie de St-George, la seigneurie St-James et, enfin, le township de Sherrington. D'après des informations tirées du recensement de 1831, le territoire de la paroisse de Saint-Édouard couvrait les seigneuries de St-George, de St-James et de Thwaite, de même que le township de Sherrington. Enfin, dans le comté de Saint-Hyacinthe, la subdivision de Saint-Pie ( ${ }^{\circ} 61$ ), telle qu'elle est définie dans le recensement de 1831, se divise en deux entités distinctes pour les élections scolaires: la paroisse catholique de Saint-Pie et la paroisse protestante d'Abbotsford.

Les comptes rendus électoraux dont nous disposons pour la première phase des écoles de syndics se répartissent assez bien dans le territoire. Nous disposons d'au moins un compte rendu pour 85 des 104 localités de la région (en excluant la paroisse de Notre-Dame-de-Montréal). L'absence de comptes rendus touche quatre paroisses rurales de l'île de Montréal ainsi qu'une quinzaine de localités situées, pour la plupart, à la périphérie 
de la région. Nous disposons d'un seul compte rendu pour une dizaine de localités dispersées sur le territoire. La majorité des localités ont laissé deux comptes rendus concernant habituellement des élections tenues en 1830 et en 1831. Par ailleurs, nous disposons pour onze localités de trois comptes rendus et pour sept autres de quatre comptes rendus et plus.

La plupart des comptes rendus renvoient à des élections annuelles de syndics pour une même localité. C'est d'ailleurs le cas de toutes les localités pour lesquelles nous disposons de deux ou de trois comptes rendus d'élection. Cependant, les huit localités qui comptent quatre comptes rendus et plus correspondent généralement à des situations particulières. Le nombre élevé des comptes rendus pour Sainte-Élizabeth $\left(\mathrm{n}^{\circ} 6\right)$, pour Sorel ( $\left.\mathrm{n}^{\circ} 44\right)$, pour Varennes ( $\mathrm{n}^{\circ} 52$ ), pour Saint-Édouard $\left(\mathrm{n}^{\circ} 78\right)$ et pour Saint-Pie $\left(n^{\circ} 61\right)$ renvoie aux redécoupages institutionnels opérés pour la tenue d'élections scolaires dans un secteur spécifique de ces localités. Les paroisses de Saint-Damase ( $\mathrm{n}^{\circ}$ 60) et de Saint-Jean-Baptiste-de-Rouville $\left(n^{\circ} 69\right)$ cumulent par ailleurs quatre élections pour une seule et même unité territoriale. Dans ces deux paroisses catholiques, en 1829, une première élection avait été invalidée vraisemblablement en raison de l'élection d'un curé ne possédant pas de biens fonciers dans la paroisse ${ }^{50}$. Enfin, la paroisse de Saint-Esprit ( $\left.\mathrm{n}^{\circ} 18\right)$ dans le comté de Lachenaye a tenu quatre élections scolaires annuelles en 1829, 1830, 1831 et 1832 .

Dans la seconde phase des écoles de syndics, les élections ont été tenues à l'échelle des arrondissements scolaires. Les 189 comptes rendus électoraux retracés dans les minutes notariales se répartissent de manière beaucoup moins équilibrée dans l'ensemble de la région de Montréal (carte 3). Nous constatons une meilleure représentation des localités situées sur la rive sud du fleuve Saint-Laurent. De plus, les localités comptant plus de sept comptes rendus se situent essentiellement sur la rive sud. Les paroisses de Chambly ( $\mathrm{n}^{\circ}$ 65), de Sorel $\left(\mathrm{n}^{\circ} 44\right)$ et de Sainte-Marie-deMonnoir ( $\left.\mathrm{n}^{\circ} 70\right)$ comptent respectivement 14, 16 et 19 comptes rendus. Les dix localités du comté de Berthier où se concentrent six des onze paroisses de la rive nord du fleuve pour lesquelles nous disposons d'au moins un compte rendu cumulent seulement treize cas. Cette distribution inégale des comptes rendus électoraux limite donc la représentativité de notre étude des syndics qui ont été élus à l'échelle des arrondissements entre 1832 et 1836 .

50. Dans ces deux paroisses, le curé avait été élu lors de la première élection, mais n’est plus parmi les syndics à la suite de la deuxième élection. 


\section{Carte 3}

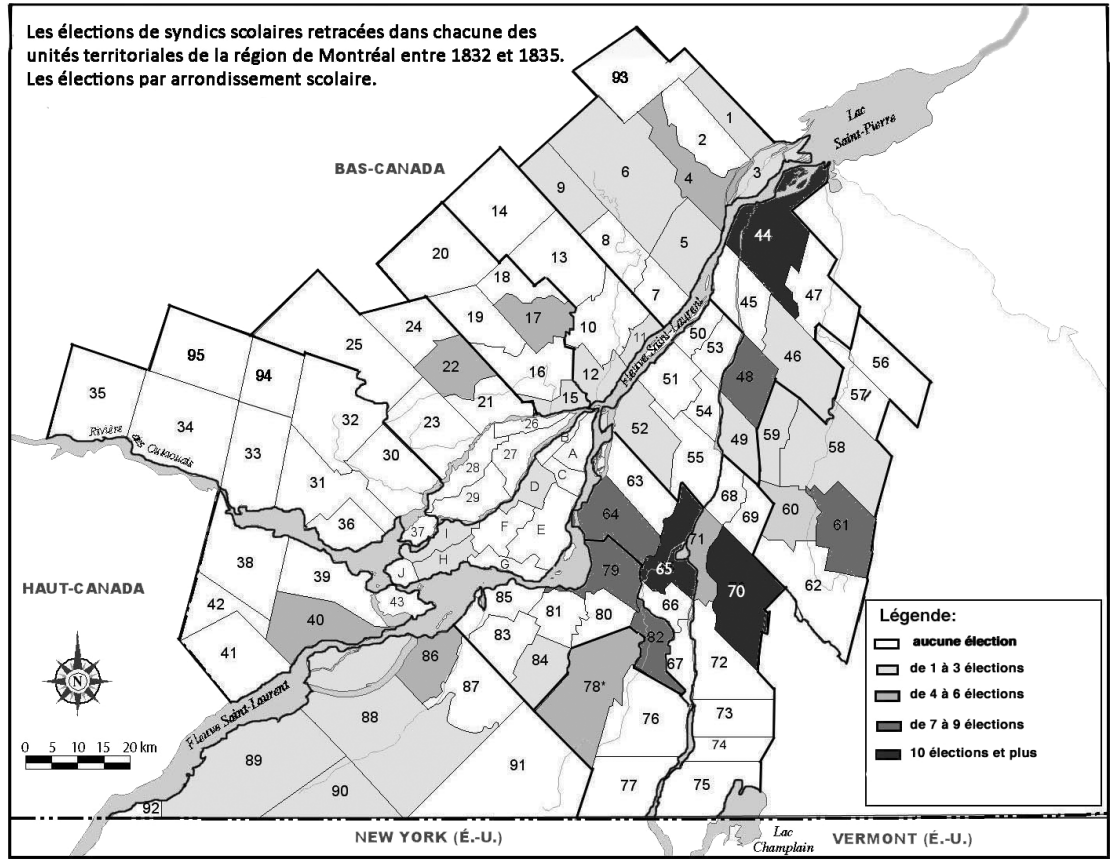

\section{LE STATUT SOCIAL DES SYNDICS: DEUX INDICATEURS PRINCIPAUX}

Nous employons deux indicateurs principaux pour déterminer le profil social des syndics scolaires: les statuts socioprofessionnels et la superficie des terres possédées. Les déclarations de professions ou de statuts dans les comptes rendus électoraux fournissent une première série de données. Ces derniers permettent d'identifier les statuts socioprofessionnels de $19,0 \%$ des élus lors de la première phase des écoles de syndics, de 1829 à 1832 , et de $40,8 \%$ des élus dans la seconde phase, de 1832 à 1836 . Le pourcentage plus élevé lors de la seconde phase découle du relevé plus fréquent des statuts socioprofessionnels dans les minutes notariales que dans le Book of School Trustees. Par ailleurs, nous soupçonnons un biais favorable dans ces deux sources à l'enregistrement des statuts socioprofessionnels expressément identifiables à la notabilité : curés, marchands, médecins, notaires ou seigneurs. Nous avons donc cherché à accroître la représentativité des autres statuts socioprofessionnels.

Dans cette optique, nous disposons d'une banque pertinente de données pour la plupart des localités du terrain d'enquête: le relevé du nom des chefs de ménage, de leurs statuts ou de leurs professions lors du recensement de 1831. Nous avons effectué un jumelage manuel des données en 
identifiant dans chacune des subdivisions du recensement de 1831 (cantons, paroisses ou seigneuries) les syndics élus lors des élections scolaires tenues dans les unités territoriales correspondantes. Nous avons privilégié les statuts ou les professions déclarés dans les rapports d'élection lorsque ces données étaient disponibles. Nous avons ensuite identifié à partir du recensement la profession et le statut des autres syndics lorsque, dans une même unité territoriale, un seul chef de ménage portait le nom du syndic élu ou lorsque des homonymes déclaraient la même profession.

Les déclarations de statuts ou de professions lors du recensement de 1831 ne sont pas disponibles pour les paroisses rurales de l'île de Montréal, pour l'ensemble du comté de Chambly ainsi que pour les townships de Godmanchester, Hemmingford et Hinchinbrooke dans le comté de Châteauguay. Par ailleurs, nous disposons seulement de déclarations partielles des statuts et des professions pour les comtés de Vaudreuil et de Verchères ainsi que pour les paroisses de Saint-Clément, Sainte-Martine et Saint-Thimothée dans le comté de Châteauguay. Dans ces derniers comtés ou parties de comtés, les recenseurs ont précisé la plupart des statuts ou des professions des chefs de ménage autres que cultivateurs en identifiant le curé, les marchands, les médecins, les notaires et les seigneurs et en notant le métier des artisans. Nous pouvons donc utiliser ces informations du recensement de 1831 en tentant de réduire le biais éventuel de ces déclarations partielles. Nous avons classé les chefs de ménage sans déclaration de statuts ou de professions de ces comtés comme cultivateurs lorsqu'ils déclaraient posséder une terre d'au moins deux hectares ${ }^{51}$.

Grâce à cette nouvelle source, nous avons identifié le statut socioprofessionnel de $71,7 \%$ des syndics scolaires élus lors de la première phase des écoles de syndics et de $62,9 \%$ des syndics scolaires élus lors de la seconde phase $\mathrm{e}^{52}$. Certains statuts liés à la notabilité demeurent favorisés, mais dans une proportion moindre qu'en utilisant seulement les déclarations des comptes rendus électoraux.

La possession de biens fonciers est aussi une composante importante de la richesse et du statut social dans le monde rural. Nous avons voulu

51. Dans ce texte, nous présentons nos données sur la superficie des terres en hectares. Une propriété de 2 hectares correspond dans les mesures employées à cette époque à un lopin de 5,9 arpents dans la zone seigneuriale ou de 4,9 acres dans la zone des cantons.

52. Ces pourcentages des syndics dont nous avons identifié le statut socioprofessionnel sont respectivement de $67,4 \%$ pour la première phase, de 1829 à 1832 , et de $61,1 \%$ pour la seconde phase, de 1832 à 1836, lorsque nous ne classons pas comme cultivateurs les chefs de ménage des comtés de Châteauguay, de Chambly, de Verchères qui n’ont pas de profession ou de statut lors du recensement de 1831, mais qui possèdent des terres de deux hectares et plus. 
utiliser ce critère de la propriété foncière pour approfondir l'étude sociale des syndics scolaires élus entre 1829 et 1836 . Nous avons donc employé les données disponibles sur la superficie des terres possédées par les chefs de famille au recensement de 1831 . Certes, la superficie de la terre reflète souvent mal la valeur réelle d'un bien foncier en milieu rural ${ }^{53}$. Mais cet indicateur demeure toutefois utile pour tenter de mesurer le degré de différenciation sociale entre les syndics, surtout au sein du groupe des cultivateurs.

Le recensement de 1831 souffre des carences déjà identifiées pour l'étude des statuts socioprofessionnels dont l'absence de données dans certains comtés ou dans certaines subdivisions ${ }^{54}$. Cette étude de la propriété foncière rencontre des obstacles additionnels. Nous devions d'abord tenir compte des unités de mesure différentes employées dans les cantons et dans les localités de la zone seigneuriale ${ }^{55}$. De plus, dans certaines localités, les données sur la superficie des terres possédées sont incomplètes ou difficiles à traiter ${ }^{56}$.

Nous avons procédé, comme pour l'étude des statuts socioprofessionnels, à un jumelage de données disponibles à partir des noms des syndics dans les rapports d'élection et des noms des chefs de ménage dans les mêmes localités (cantons, paroisses ou seigneuries) au recensement de

53. L'avancement inégal des défrichements d'une terre à l'autre, la qualité des améliorations (bâtiments, clôtures, fossés, labours), la qualité différentielle des sols agricoles et la localisation par rapport aux réseaux de communication et au marché sont autant des facteurs qui influent sur la valeur relative d'une même unité de terre en superficie. Jean Lafleur, Gilles Paquet et Jean-Pierre Wallot, «Le coût du sol dans la région de l’Assomption, 1792-1825 : enrichissement, enchérissement et liens au marché» dans C. Dessureault, John A. Dickinson et J. Goy, dir., Famille et marché $X V I^{\mathrm{e}}-\mathrm{XX} \mathrm{X}^{\mathrm{e}}$ siècles (Sillery, Septentrion, 2003), 95-114.

54. L'absence de données concernant la superficie des terres possédées est effective dans les comtés et dans les localités déjà mentionnées, de même que dans les paroisses de Saint-Françoisde-Sales et de Sainte-Rose sur l'île Jésus où le recenseur n'a pas indiqué le nombre d'arpents possédés par les chefs de ménage de ces deux localités.

55. Dans les localités de la vieille zone seigneuriale, l'arpent constitue l'unité de base pour mesurer la superficie des terres tandis que dans les cantons majoritairement peuplés d'Anglophones, cette unité de mesure est plus généralement l’acre. Nous présentons nos données sur la superficie des terres en hectares. L'arpent carré $=0,34$ hectare tandis l'acre $=0,41$ hectare.

56. Par exemple, dans la paroisse de Saint-Sulpice $\left(n^{\circ} 11\right)$, le recenseur n’a pas systématiquement noté la superficie possédée par les chefs de ménage propriétaires. Nous avons alors constaté que ce recenseur précisait le nombre d’arpents possédés seulement lorsqu'une terre n'était pas entièrement défrichée. Dans les autres cas, la superficie cultivée de la terre correspondait aussi à la superficie possédée. Dans d'autres paroisses, comme à Varennes ( $\left.\mathrm{n}^{\circ} 52\right)$, le travail du recenseur a rendu hasardeux le repérage précis de la superficie possédée par certains chefs de ménage de la paroisse compte tenu de l'absence de concordance des lignes entre la première et la seconde page de données du recensement concernant une même série de ménages. 
1831. La perte dans le jumelage des données liée à l'homonymie a été plus grande pour la superficie des terres possédées. Pour identifier le statut socioprofessionnel d'un syndic, nous avions conservé la déclaration des deux, trois ou quatre chefs de ménage portant le même nom dans une localité si ces derniers déclaraient un même statut ou une même profession. Par contre, nous avons écarté la plupart de ces mêmes chefs de ménage pour déterminer la propriété foncière des syndics puisque ceux-ci déclaraient habituellement posséder des propriétés d'une superficie inégale. Enfin, cette étude de la superficie des terres possédées par les syndics scolaires ne tient pas compte de la grande propriété seigneuriale possédée, à titre de fiefs, par les seigneurs ${ }^{57}$.

Le pourcentage de syndics pour lesquels nous avons retrouvé des informations concernant la propriété foncière est de $63,1 \%$ pour la première phase des écoles de syndics, de 1829 à 1832, et de $51,5 \%$ pour la seconde phase, de 1832 à 1836 . Pour les syndics appartenant au groupe des cultivateurs où la superficie des terres possédées est un facteur encore plus déterminant du statut social, ces pourcentages sont respectivement de $90,5 \%$ pour la première phase et de $73,3 \%$ pour la seconde.

\section{LES STATUTS SOCIOPROFESSIONNELS DES SYNDICS SCOLAIRES}

Le classement des individus en groupes socioprofessionnels vise à repérer un certain ordre hiérarchique dans une société. Les individus d'un même groupe doivent donc remplir sensiblement les mêmes rôles dans le système de production et d'échange, et occuper des places équivalentes dans l'organisation sociale. Ils devraient aussi posséder des niveaux de fortune relativement similaires. Dans la société réelle, cette égalité de la richesse au sein d'un même groupe socioprofessionnel n'existe toutefois pas vraiment ${ }^{58}$.

Nous avons tout de même établi notre classification à partir des mentions de professions et de statuts tout en étant conscient de la dimension

57. Par exemple, pour la paroisse de Saint-Hyacinthe ( $\mathrm{n}^{\circ} 58$ ), nous avons éliminé de nos données la déclaration du seigneur Dessaulles qui incluait à l'évidence l'ensemble des terres concédées de la seigneurie de Saint-Hyacinthe. Le recenseur avait noté le chiffre de 158,750 à la rubrique concernant le nombre d’arpents possédés par ce chef de ménage.

58. C. Dessureault, «L'égalitarisme paysan dans l’ancienne société rurale de la vallée du SaintLaurent: éléments pour une ré-interprétation", RHAF, 40,3 (hiver 1987): 373-407; Claude Pronovost, La bourgeoisie marchande en milieu rural (1720-1840) (Sainte-Foy, Les Presses de l'Université Laval, 1998), 230 p.; G. Paquet et J.-P. Wallot, «Structures sociales et niveaux de richesse dans les campagnes du Québec, 1792-1812», Bulletin d'histoire de la culture matérielle, 17 (printemps 1983): 25-44. 
perfectible de ce classement. Nous avons placé en haut de l'échelle une première série de quatre groupes identifiés de prime abord à un statut élitaire dans la société rurale de l'époque: les seigneurs, les membres du clergé, les marchands et les professionnels. Nous avons inséré entre ces catégories le seul syndic identifié comme agent seigneurial. Nous avons ensuite placé deux catégories intermédiaires moins directement associées à une position élitaire : les bourgeois ${ }^{59}$ et les aubergistes. Puis, nous avons créé un groupe spécifique, nommé cols blancs, pour regrouper dans une même catégorie les quelques syndics qui exerçaient le métier de maîtres d'école, d'huissier ou d'inspecteur des douanes. Les deux groupes subséquents de cette classification sont les artisans et les cultivateurs. Dans la société rurale bas-canadienne, ces deux groupes concentrent la majorité des chefs de ménage. Ces derniers sont pour la plupart propriétaires de leurs moyens de production et de leurs habitations. Enfin, au bas de l'échelle, nous avons la catégorie des journaliers, composée principalement de locataires qui doivent vendre leur force de travail pour survivre. Dans la période étudiée, ce prolétariat rural est en pleine expansion.

Les groupes socioprofessionnels qui sont habituellement identifiés à la notabilité (seigneurs, marchands, membres du clergé et des professions libérales) affichent une présence importante dans la nouvelle institution scolaire durant la première phase des écoles de syndics (voir le tableau 1). Ces notables qui constituent en 1831 moins de $2 \%$ des chefs de ménage dans 12 localités rurales de la région de Montréal ${ }^{60}$ représentent près de

59. Nous pouvons constater les origines sociales plutôt diversifiées des individus identifiés comme bourgeois. Parmi les syndics scolaires qui appartiennent à ce groupe, nous avons repéré des cultivateurs et des marchands retraités, deux fils de seigneurs et un ancien officier militaire. Néanmoins, l'emploi de cette déclaration demeure selon nous l'indice d'un certain statut élitaire. Le cas des trois bourgeois qui ont été élus à plusieurs reprises sur les conseils scolaires de la paroisse de Saint-Roch-l'Achigan entre 1829 et 1832 est révélateur. Il s'agit de trois membres influents de l'élite locale dont le député Charles Courteau, un ancien marchand, l'ancien député Jacques Archambault, un cultivateur qui a réussi à se hisser parmi les principaux acteurs politiques de sa paroisse, voire de sa région, et enfin le major de milice Protet Dodet D’Orsonnens, un ancien officier militaire. Pour des informations additionnelles sur les élites institutionnelles de cette paroisse, voir J.-R. Thuot, "Élites locales... », op. cit.

60. Pour évaluer le poids relatif des statuts socioprofessionnels, nous avons sélectionné 12 paroisses dans 6 comtés différents dont 3 sur la rive sud et 3 sur la rive nord du Saint-Laurent. Le pourcentage de notables varie dans ces localités de $0 \%$ (Sabrevois) à 3,2\% (Saint-Denis-surRichelieu). Par ailleurs, en 1831, ces notables représentent 1,8\% des 2408 chefs de ménage de la seigneurie de Saint-Hyacinthe. Dans les 5 paroisses de cette seigneurie, leur pourcentage varie de $0,6 \%$ des chefs de ménage à Saint-Damase jusqu'à 2,9\% à Saint-Hyacinthe dont le bourg compte près de 1000 habitants. C. Dessureault, «Crise et modernisation? La société rurale maskoutaine durant le premier tiers du XIX ${ }^{\mathrm{e}}$ siècle», RHAF, 42,3 (hiver 1989): 366-367. 
$27 \%$ des individus élus aux conseils scolaires ${ }^{61}$ et ils accaparent environ $30 \%$ des mandats. Ces pourcentages atteignent près de $31 \%$ des individus et de $35 \%$ des mandats en incluant dans le groupe des notables l'agent seigneurial, les bourgeois et les aubergistes. Parmi les notables ruraux, les mieux représentés au sein des syndics scolaires sont dans l'ordre les marchands, les membres du clergé et les professionnels. Les seigneurs arrivent loin derrière ces autres groupes de notables ${ }^{62}$. Le nombre de marchands et de curés élus sur les conseils scolaires est relativement similaire. Puisque chaque localité compte plusieurs marchands, leur participation est moins forte que celle du clergé. Elle demeure néanmoins élevée puisque les marchands représentent de 9 à $10 \%$ des élus et des mandats.

Les curés accaparent environ $10 \%$ des mandats sur les nouveaux conseils scolaires malgré l'opposition des dirigeants de l'Église catholique et surtout de l'évêque auxiliaire de Montréal, $\mathrm{M}^{\mathrm{gr}}$ Lartigue, envers les écoles de syndics ${ }^{63}$. Au début des années 1830, le bas clergé exprime ainsi une certaine autonomie face aux autorités ecclésiastiques lorsqu'un différend touche leur rôle dans la vie civile locale plutôt qu'une question de doctrine religieuse. Néanmoins, cette participation au fonctionnement des écoles de syndics ne signifie pas nécessairement une adhésion des curés de campagne aux principes d'une école publique et laïque. L'objectif de plusieurs est sans doute d'influencer de l'intérieur le nouveau système scolaire. Sauf de rares exceptions, les notables laïques n'ont visiblement pas cherché à évincer le clergé des conseils scolaires ${ }^{64}$.

61. Le terme de conseil scolaire est employé dans ce texte par commodité afin de varier le vocabulaire servant à désigner les syndics scolaires d'une même localité, car ce terme apparaît seulement dans les années 1840 lors de la création de nouvelles structures scolaires.

62. La faible proportion des seigneurs n'est pas nécessairement liée à leur désintérêt envers la nouvelle institution. Elle découle plutôt du nombre limité de seigneurs aptes à occuper une telle charge. À partir d'un relevé que nous avons effectué dans les recensements et dans d'autres sources, seulement 24 des localités de la région comptait une ou plusieurs familles seigneuriales résidantes et nous n'avons retracé aucun compte rendu d'élection pour 5 de ces 24 localités. Pour les 19 autres localités où ces derniers pouvaient siéger à des conseils scolaires, nous avons retracé 13 seigneurs élus dont 4 pour la seule paroisse de Varennes. Cette paroisse était alors scindée en plusieurs petites seigneuries, tandis que d'autres seigneuries couvraient plusieurs paroisses.

63. Sur la position des dirigeants de l'Église catholique par rapport aux écoles de syndics, voir L.-P. Audet, op. cit., 133-136; F. Ouellet, L’enseignement primaire: responsabilité de l’Église et de l’État", Recherches sociographiques, 1,2 (1961): 171-187.

64. Dans son étude sur l'attitude des curés de campagne par rapport à la question scolaire, R. Chabot insiste, à partir de certains exemples, sur les aspects conflictuels des rapports entre le clergé et les autres notables. Concernant l'exclusion des curés des premiers conseils scolaires, il invoque le cas de Messire Raizenne, curé à Saint-Roch-l'Achigan, qui vocifère contre les notables de cette paroisse parce qu'il n'aurait pas été accepté comme syndic (R. Chabot, op. cit., 57). Or, ce curé a été élu syndic lors des deux premières élections scolaires tenues dans cette paroisse en 


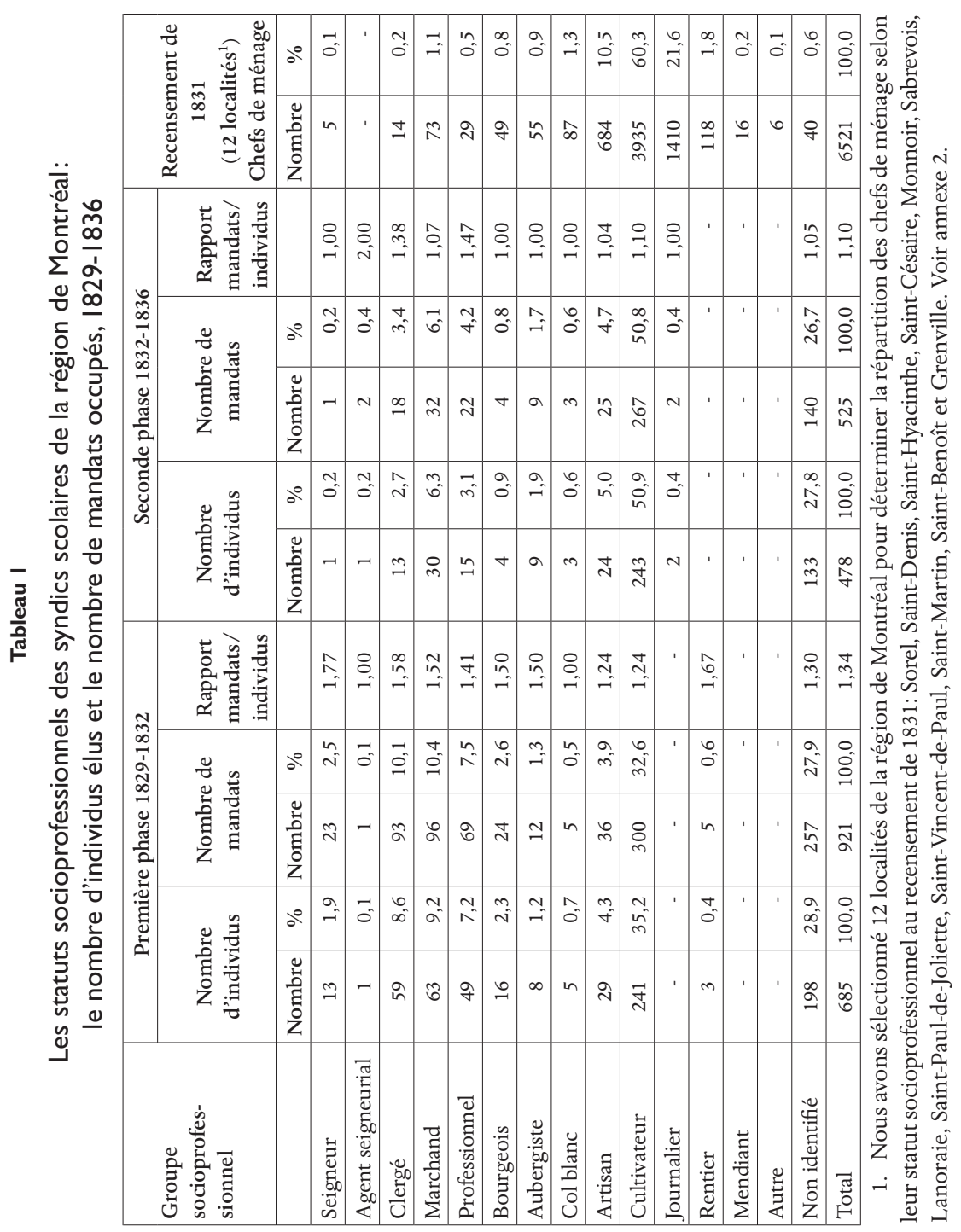

Les professions libérales participent aussi en assez grand nombre à la nouvelle institution. Nous avons identifié 3 arpenteurs, 20 médecins et

1829 et en 1830. Puis, il est effectivement absent de la liste des syndics élus en 1831. L'exclusion de ce curé est apparemment liée à un conflit qui l'opposait depuis plusieurs années au capitaine Jacques Archambault. Ce dernier a été élu au conseil scolaire de Saint-Roch en 1829, 1830 et 1831. J.-R. Thuot, «Élites locales et institutions à l'époque des Rébellions: Jacques Archambault et l'épisode du presbytère de Saint-Roch-de-l'Achigan », Histoire sociale/Social History, 38,76 (novembre 2005): 339-365. 
26 notaires parmi les syndics scolaires de la région de Montréal durant la première phase des écoles de syndics. Ces derniers représentent environ 7,5\% des élus et des mandats. Cette présence minoritaire ne permet certainement pas de présumer le contrôle de cette institution par la petite bourgeoisie des professions libérales. L'un des personnages de cette faction élitaire instruite les mieux connus dans le monde de l'éducation est le docteur Jean-Baptiste Meilleur ${ }^{65}$. Ce dernier a été élu pour la première fois comme syndic scolaire à l'Assomption lors de la deuxième élection tenue dans cette paroisse en 1831.

Nous pouvons identifier parmi les notables laïques actifs dans la nouvelle institution plusieurs partisans du Parti patriote ${ }^{66}$. Mais les partisans du Parti bureaucrate qui vivent en milieu rural ne boudent pas les écoles de syndics. Au tournant des années 1830, l'arrivée d'un nouveau gouverneur ouvre une courte période de collaboration entre les adversaires politiques conservateurs et réformistes. À Terrebonne, la famille McKenzie, qui avait été écorchée par un partisan patriote durant la crise politique sous le gouverneur Dalhousie, investit le conseil scolaire ${ }^{67}$. À Saint-Eustache, des membres des familles seigneuriales De Bellefeuille et Lambert-Dumont, qui ont été des acteurs importants dans la répression

65. Jean-Baptiste Meilleur fut le premier surintendant de l'éducation au Bas-Canada de 1842 à 1855. Dès 1828, il manifesta son intérêt pour l'éducation en publiant une série de lettres dans le journal La Minerve. Il continua à participer activement aux débats publics sur les systèmes scolaires dans les années 1830 et il contribua à la fondation du collège de l'Assomption. Le docteur Meilleur a aussi été élu député du comté de l'Assomption à la Chambre d'assemblée du Bas-Canada en 1834. Dictionnaire biographique du Canada en ligne: http://www.biographi.ca/FR/index.html, Léon Lortie, "Meilleur, Jean-Baptiste».

66. La liste des partisans du Parti patriote qui ont siégé aux conseils scolaires serait trop longue à dresser. D’après un relevé effectué dans ses bases de données par l'historien Gilles Laporte, plus d'une centaine de syndics scolaires auraient participé au mouvement insurrectionnel ou à diverses activités organisées par le mouvement patriote dans les années précédant les Rébellions. Nous le remercions pour ces précieuses informations. Par ailleurs, onze députés actifs du Parti patriote ont siégé aux conseils scolaires de leur localité respective entre 1829 et 1832 dont le seigneur Jean Dessaulles, le beau-frère de Louis-Joseph Papineau, élu à trois reprises à Saint-Hyacinthe en 1829, 1830 et 1831 . Certains anciens députés de ce parti ont aussi été élus syndics scolaires durant cette période dont Wolfred Nelson à Saint-Denis et André Papineau, à Saint-Martin.

67. Le conseiller législatif Roderick McKenzie et son fils John, marchand à Terrebonne, ont été élus syndics scolaires à Terrebonne en 1830 et 1831. Pendant la crise politique sous Dalhousie, Louis-Hypolite Lafontaine avait dénoncé la nomination par Roderick McKenzie de son fils Roderick jr, âgé de 10 ans, comme major dans la milice de la division de Terrebonne et la présence, au poste de commandant de la division de milice de l'île-Jésus, de son autre fils John qui résidait à Terrebonne, à l'extérieur des limites de cette division. La Minerve, 14 mai 1827 et 15 septembre 1828 (articles déjà cités dans C. Dessureault, «La crise sous Dalhousie. Conception de la milice et conscience élitaire des réformistes bas-canadiens, 1827-1828», RHAF, 61,2 (automne 2007): 167-199.) 
orchestrée par le même gouverneur, siègent en 1830 au même conseil scolaire que le nouveau député patriote du comté d'York, le docteur Jacques Labrie ${ }^{68}$. À Varennes, le lieutenant-colonel Lemoine de Martigny, qui avait dénoncé des officiers de milice de son bataillon pour l'organisation d'une assemblée séditieuse en 1827, est également présent dans les conseils scolaires $^{69}$. Plusieurs autres défenseurs des autorités coloniales se font aussi élire dans les conseils scolaires de leurs localités tel John Simpson à Soulanges ${ }^{70}$.

La charge de syndic scolaire n’est toutefois pas réservée aux notables des bourgs. Les cultivateurs qui représentent selon les localités de la moitié aux deux tiers des chefs de famille constituent le groupe socioprofessionnel le plus fortement représenté dans les conseils scolaires. Les cultivateurs représentent environ le tiers des élus et des mandats. Compte tenu du relevé plus fréquent des statuts socioprofessionnels liés à la notabilité dans les comptes rendus électoraux et de la présence d'une majorité d'individus appartenant aux classes populaires parmi les syndics dont le statut n’a pas été identifié, les cultivateurs constituent sans doute plus de la

68. Le lieutenant-colonel Lefebvre de Bellefeuille a été élu en 1830 sur le conseil scolaire de Saint-Eustache tandis que son frère, Antoine, et Charles Lambert-Dumont, le fils du seigneur de l'endroit, ont été élus syndics dans la même paroisse l'année suivante. Le docteur Jacques Labrie, un député patriote, a siégé à ce même conseil scolaire en 1830. Le seigneur Nicolas-Eustache Dumont fut l'un des plus farouches partisans du gouverneur Dalhousie lors de la crise de 1827. À l'été 1827, le seigneur Dumont et son colistier John Simpson, de Soulanges, furent battus aux élections dans le comté d'York par les deux candidats du Parti patriote dont le docteur Labrie. Par la suite, en juillet 1828, le seigneur Dumont, commandant de la milice dans la région, fit arrêter et condamner, à de lourdes amendes et à des peines de prison, des partisans du Parti patriote de la paroisse voisine de Saint-Benoît parce qu'ils refusaient de s'enrôler dans la milice. Le lieutenantcolonel Dumont dirigea lui-même, à Saint-Eustache, la cour martiale chargée du dossier. Le lieutenant-colonel Lefebvre de Bellefeuille, neveu du seigneur Dumont et membre de l'état-major provincial, participa aussi à la répression contre les officiers de la milice appuyant le Parti patriote lors de la crise sous Dalhousie. Certains membres de la famille Lefebvre de Bellefeuille appuyèrent toutefois le Parti patriote. Pour plus de détails sur ces conflits, voir Ibid.

69. Le lieutenant-colonel Jacques Lemoine de Martigny, l'un des seigneurs de Varennes, a été élu syndic scolaire en 1830 à Varennes (Grand Côteau) et son fils Jacques, capitaine de milice, l'année suivante. Durant la crise sous Dalhousie, les dénonciations du lieutenant-colonel de Martigny ont entre autres entraîné la destitution du major Xavier Mailhot, seigneur de Verchères et de Contrecœur. Pour plus de détails sur ces conflits, voir Ibid.

70. John Simpson a été élu syndic scolaire dans la paroisse de Soulanges en 1830. Ancien secrétaire particulier du gouverneur Dalhousie, il occupe depuis 1822 le poste de receveur des douanes et d'inspecteur des écluses à Côteau-du-Lac. Simpson avait été élu député du comté d'York en 1824, puis défait lors de l'élection controversée de 1827. Le gouverneur Dalhousie l'avait nommé la même année lieutenant-colonel dans la milice et commandant de la division de Vaudreuil. Durant les Rébellions de 1837-1838, John Simpson dirige un groupe de volontaires loyalistes à Côteau-du-Lac. Dictionnaire biographique du Canada en ligne : http ://www.biographi.ca/ FR/index.html, J. B. Thompson, «Simpson, John». 
moitié des élus et des mandats durant la première phase des écoles de syndics $^{71}$. La présence des artisans renforce la place relative des classes populaires au sein de la nouvelle institution. Cependant, le pourcentage des artisans, moins de $5 \%$ des élus et des mandats, est inférieur au poids de ce groupe dans la société rurale. Plus bas dans l'échelle sociale, les journaliers qui constituent environ le cinquième des chefs de ménage ruraux n'ont pas accès à cette charge publique ${ }^{72}$.

La loi de 1832 modifie peu les critères de qualification pour participer aux élections scolaires et pour occuper la charge de syndics. Le droit d'élire des syndics scolaires est désormais réservé aux "chefs de Famille de chaque arrondissement d'École qualifiés pour voter à l'élection des Membres pour servir dans l'Assemblée ${ }^{73}$ ». Dans les comtés ruraux, ce droit de participer à l'élection des députés de la Chambre d'assemblée est réservé aux personnes âgées de plus de 21 ans possédant un bien foncier de la valeur nette annuelle, en sus des rentes et des autres charges, d'au moins $£ 2$ sterling ou 44 chelins et 5 deniers un farthing cours halifax ${ }^{74}$. Le maintien d'un cens électoral lié à la valeur de la propriété contribue à exclure les plus pauvres. Cependant, l'adoption des arrondissements comme unité de base de la démocratie scolaire va diminuer la sélectivité sociale des élus.

La part relative des notables (seigneurs, clergé, marchands et professions libérales) chute considérablement de la première à la seconde phase des

71. En consultant d'autres sources, nous avons constaté la présence de quelques notables parmi ces syndics dont la profession, ou le statut, n'avait pas été identifiée à partir des comptes rendus électoraux et du recensement de 1831 . Nous ne les avons pas classés parmi les notables car nous n'avons pas effectué cette démarche de manière systématique. Parmi les cas relevés, nous pouvons noter Jacques Lemoine de Martigny fils, le fils du seigneur de Varennes; Xavier Mailhot fils, le fils du seigneur de Contrecœur et de Verchères; Antoine Lefebvre de Bellefeuille, l'un des membres de la famille seigneuriale des Milles-îles; Lawrence G. Brown, un marchand de Beauharnois appuyant le Parti patriote; et de Louis Marchand, un marchand de Saint-Jean-sur-Richelieu appuyant aussi le Parti patriote.

72. Dans les 12 localités sélectionnées, les journaliers regroupent environ le cinquième des chefs de ménage. Leur proportion varie de $7 \%$ dans un canton de peuplement récent (Grenville) à $39 \%$ dans une ancienne paroisse située sur les bords du fleuve Saint-Laurent (Lanoraie). Dans la seigneurie de Saint-Hyacinthe, les journaliers représentent 13,3\% de l'ensemble des 2408 chefs de ménage. Dans les 5 paroisses de cette seigneurie, leur proportion varie de 10,6 à 15,4\% des chefs de ménage. C. Dessureault, "Crise et modernisation... », op. cit., 366-367.

73. Actes y mentionnés et pour encourager ultérieurement les Écoles élémentaires dans les Campagnes de cette Province, Lois de la province du Bas-Canada, 2, Guill. IV, ch. 26, 25 février 1832.

74. Pour une synthèse des lois électorales régissant le droit de vote et le droit des élections au Bas-Canada, voir Nathalie Picard, Les femmes et le vote au Bas-Canada de 1792 à 1849, mémoire de maîtrise (Histoire), Université de Montréal, 1992, 34-45. 
écoles de syndics, soit de $27 \%$ des élus et de $30 \%$ des mandats à seulement $12,3 \%$ des élus et $13,9 \%$ des mandats. Les bourgeois voient aussi leur pourcentage décliner. Nous avons par ailleurs identifié un seul seigneur parmi les syndics élus à l'échelle des arrondissements, soit le seigneur Lemoine de Martigny à Varennes. Quelques curés de campagne participent encore à la gestion locale des écoles d'Assemblée malgré les critiques de plus en plus acerbes contre ce système dans le journal catholique conservateur L'Ami du Peuple $e^{75}$. Parmi ceux-ci, le curé de Longueuil, Augustin Chaboillez, dont le différend avec $\mathrm{M}^{\mathrm{gr}}$ Lartigue est notoire ${ }^{76}$, démontre un intérêt continu pour les écoles de syndics en se faisant élire en 1832 et en 1834 dans l'un des arrondissements de sa paroisse. Le 17 mai 1834, un auteur anonyme relate dans le journal L'Ami du Peuple la visite effectuée le 30 avril précédent par ce curé à l'école du village de Longueuil où il a "fait un discours encourageant M. l'instituteur à continuer ses soins, et son assiduité, et félicitant les élèves sur leurs progrès ${ }^{77}$ ».

Après 1832, la gestion locale des écoles incombe de plus en plus aux cultivateurs. Dans la première phase des écoles de syndics, les conseils scolaires qui comprenaient cinq membres comptaient fréquemment au moins un ou deux notables des bourgs. Dans la seconde phase des écoles de syndics, les conseils scolaires qui comprennent désormais trois membres sont souvent composés exclusivement de cultivateurs, surtout dans les arrondissements à l'extérieur des bourgs.

\section{LA DIFFÉRENCIATION DANS L'ESPACE DU POIDS DES NOTABLES ENTRE I829 ET I832}

Dans la première phase des écoles de syndics, les notables occupent une proportion importante des sièges dans les conseils scolaires. Toutefois,

75. Fondé en 1832, L'Ami du Peuple, de l'Ordre et des Lois est un journal catholique foncièrement conservateur. Ce journal montréalais était étroitement lié aux intérêts des prêtres du Séminaire de Saint-Sulpice même si ses dirigeants et propriétaires officiels, John Jones et Pierre-Édouard Leclère, de même que ses deux rédacteurs, Michel Bibaud (jusqu'en 1833) et Alfred Rambau (de 1833 à 1840), étaient laïques.

76. Augustin Chaboillez est né à Montréal le $1^{\text {er }}$ décembre 1773 au sein d'une riche famille marchande impliquée dans la traite des fourrures. D’abord vicaire à Longueuil, puis curé au Sault-au-Récollet, l'abbé Chaboillez est nommé à la cure de Saint-Antoine-de-Longueuil par $\mathrm{M}^{\mathrm{gr}}$ Plessis en 1806 et il demeure dans cette paroisse jusqu'à son décès le 28 août 1834. En 1822, il mène une cabale, avec le curé François Pigeon, contre l'établissement de Jean-Jacques Lartigue comme évêque auxiliaire de Montréal. L’année suivante, il publie un pamphlet questionnant la validité de cette nomination. Cette publication suscite une vive controverse au sein du clergé canadien durant laquelle les adversaires de l'abbé Chaboillez lui reprochèrent son gallicanisme et son libéralisme. Dictionnaire biographique du Canada en ligne: http://www.biographi.ca/FR/index. html, Gilles Chaussé, "Chaboillez, Augustin».

77. L'Ami du Peuple, de l'Ordre et des Lois, le 17 mai 1834. 
leur présence varie considérablement d'une localité à l'autre. Nous avons cartographié cette variation dans l'espace de la présence de notables dans les conseils scolaires entre 1829 et 1832 (carte 4). Nous avons calculé pour chacune des localités de la région de Montréal le pourcentage de mandats occupés par des notables durant la première phase des écoles de syndics. Les notables occupent plus de $80 \%$ des mandats dans seulement huit localités de la région pour lesquelles nous disposons de données suffisantes pour évaluer leur place relative. La plupart de ces localités abritent des bourgs ou des villages importants à l'époque: Saint-Hyacinthe (n $\left.{ }^{\circ} 58\right)$, Saint-Ours ( $\left.{ }^{\circ} 45\right)$, Saint-Denis ( $\left.\mathrm{n}^{\circ} 48\right)$, L'Assomption ( $\left.\mathrm{n}^{\circ} 10\right)$, Terrebonne $\left(\mathrm{n}^{\circ} 21\right)$ et Saint-Eustache ( $\left.\mathrm{n}^{\circ} 30\right)$. Les seigneurs et les marchands exercent souvent une influence considérable sur la vie locale de ces localités comme dans la paroisse de Saint-Paul-de-Lavaltrie où le seigneur Barthelémy Joliette a fondé le village de l'Industrie ( $\left.\mathrm{n}^{\circ} 8\right)$. Dans la localité de Sorel ( $\mathrm{n}^{\circ} 44$ ), la division en deux entités des nouveaux conseils scolaires, l'un pour le bourg de William Henry et l'autre pour la paroisse, contribue à restreindre le pourcentage global des notables dans cette localité dotée d'un gros bourg. Par ailleurs, la présence des notables est également moins forte dans les conseils scolaires des localités de Berthier $\left(\mathrm{n}^{\circ} 4\right)$ et de Laprairie ( $\mathrm{n}^{\circ} 79$ ) qui abritent pourtant, au tournant des années 1830 , des

Carte 4

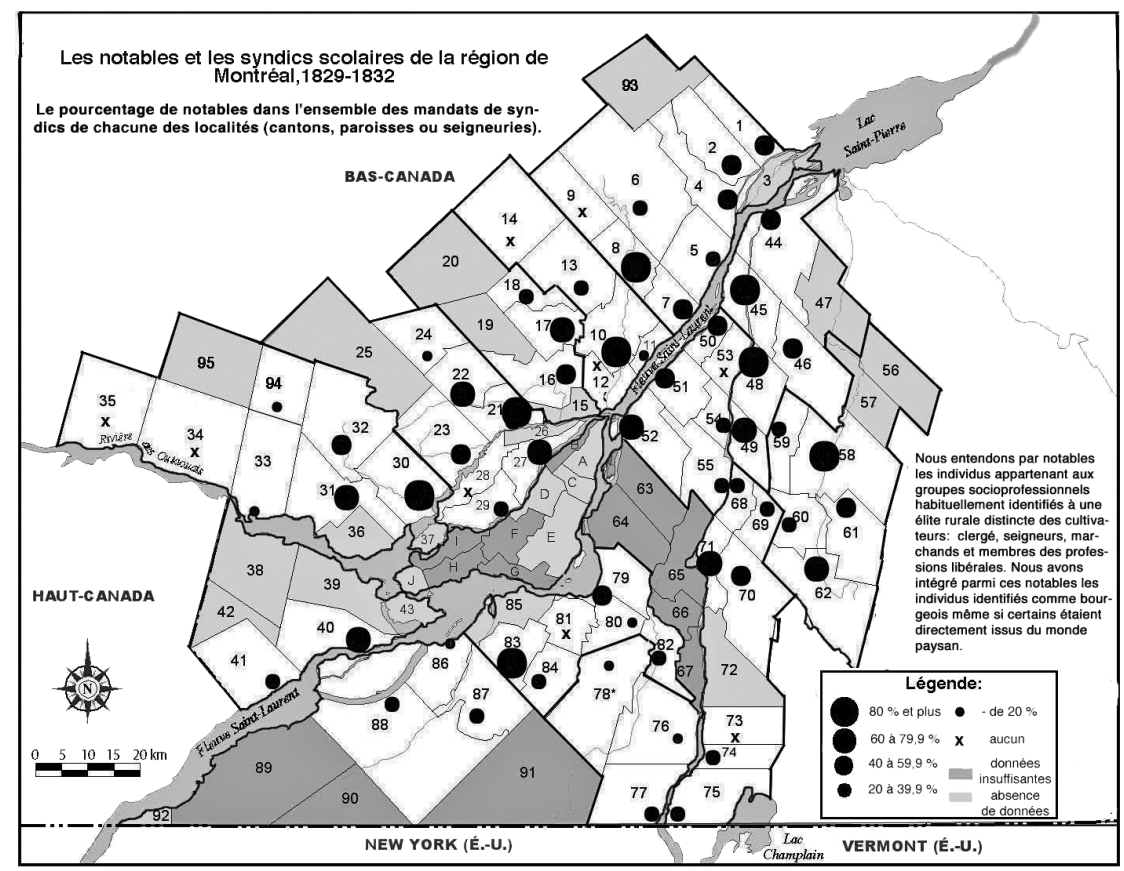


bourgs populeux. Les notables accaparent entre 60 à 79,9\% des mandats dans 9 autres localités de la région de Montréal et ils détiennent entre 40 et 59,9\% des mandats dans 14 autres localités. Dans 31 des 66 localités pour lesquelles nous disposons de données, les notables occupent ainsi au moins $40 \%$ des mandats.

Dans les 35 autres localités, les cultivateurs sont fortement majoritaires au sein des nouveaux conseils scolaires. Dans 19 de ces 35 localités où la proportion de notables varie entre 20 et $39,9 \%$ des mandats, les conseils scolaires comptent tout de même régulièrement un curé, un marchand, un médecin ou un notaire. La présence de notables dans les conseils scolaires est finalement intermittente dans huit localités et invisible dans huit autres.

\section{LES SYNDICS CULTIVATEURS ENTRE I829 ET I832: ENTRE CONDITIONS LOCALES ET STATUT SOCIAL}

Dans des localités dotées d'un bourg important, il est certainement difficile à des cultivateurs de se faufiler au sein des conseils scolaires. Le village de Saint-Hyacinthe atteint en 1831 près d'un millier d'habitants et compte, en plus du curé et du seigneur, douze marchands et quatre professionnels chefs de ménage ${ }^{78}$. Les notables y accaparent la plupart des 15 mandats de syndics disponibles dont le seigneur Dessaulles et le curé Girouard, deux personnages influents, qui ont respectivement été élus à trois reprises en 1829,1830 et 1831 . Malgré la présence de nombreux notables dans cette localité, deux cultivateurs accèdent à un poste dans le conseil scolaire en 1829 et en 1831 : Ambroise Gendron et Louis Raynault-Blanchard. Ces deux cultivateurs sont d'importants propriétaires fonciers. En 1831, la superficie de leurs terres est respectivement de 178,5 et de 125,8 hectares. Ce sont aussi deux capitaines dans la milice locale. Par ailleurs, RaynaultBlanchard avait été marguillier en charge de la fabrique paroissiale en $1826^{79}$ et l'année précédant son élection au conseil scolaire, il avait été l'un des deux députés élus dans le comté de Saint-Hyacinthe ${ }^{80}$.

78. L'ensemble de la paroisse compte alors, en plus du curé et du seigneur, 17 marchands et 5 professionnels chefs de ménage. C. Dessureault, "Crise et modernisation... », op. cit., 366-367.

79. Archives de l'Évêché de Saint-Hyacinthe (AESH), Isidore Desnoyers, Histoire de la paroisse de Saint-Hyacinthe, cahier manuscrit, vers 1880. Pour sa part, Ambroise Gendron est élu en 1833 au conseil de la fabrique de la nouvelle paroisse de Sainte-Rosalie et en est le marguillier en charge en 1835. AESH, I. Desnoyers, Histoire de la paroisse de Sainte-Rosalie, cahier manuscrit, vers 1880.

80. Le comté de Saint-Hyacinthe élisait alors deux députés. Le seigneur Dessaulles a terminé au premier rang du scrutin lors de cette élection. Louis Raynault-Blanchard est arrivé second devançant deux marchands du village de Saint-Hyacinthe dont le colistier du seigneur. C. Dessureault, «L'élection de 1830 dans le comté de Saint-Hyacinthe : les solidarités paroissiales, sociales et familiales ", Histoire sociale/Social History, 36,72 (novembre 2003): 281-310. 
À l'autre bout du spectre, les cultivateurs occupent la plupart des mandats de syndics scolaires dans certaines localités et la sélectivité sociale semble y opérer avec moins de vigueur. Cependant, nous devons regarder d'un peu plus près ces localités. Nous proposons donc une visite rapide des paroisses de Saint-Jean-Baptiste-de-Rouville et de Saint-Damase où des cultivateurs contrôlent les conseils scolaires entre 1829 et 1832. Ces deux paroisses ont vécu quatre élections durant cette période dont deux en 1829.

Dans la paroisse de Saint-Jean-Baptiste, 8 cultivateurs accaparent 14 des 20 mandats de syndics entre 1829 et 1832 . Le curé de la paroisse a été élu à deux reprises en 1829 et 1830 . Mais, en 1829 , ce curé qui ne possédait vraisemblablement pas de biens fonciers dans la paroisse a dû abandonner sa charge de syndic. Le marchand Jean-Baptiste Sénécal a été élu lors de la nouvelle élection tenue en 1829 et une seconde fois en 1831. Les deux dernières charges ont été occupées par des individus dont nous n'avons pas retracé la profession.

Parmi les cultivateurs, les deux frères Blanchard dit Renaud ${ }^{81}$, Louis et Étienne, capitaine et enseigne dans la milice, ont été élus à deux et à trois reprises au conseil scolaire. C'est d'ailleurs Louis qui, en tant que plus ancien officier de milice de la paroisse, avait présidé les deux premières élections en $1829^{82}$. Leur cousin par alliance, Jean-Baptiste Poirier, a également été élu à deux reprises au conseil scolaire de cette localité en 1829 et 1830. Ces trois cultivateurs possèdent par ailleurs en 1831 des propriétés foncières d'une superficie respective de 119 et de 66,6 hectares pour les frères Blanchard et de 68,7 hectares pour Poirier. Les autres cultivateurs qui ont siégé au conseil scolaire sont aussi de gros propriétaires fonciers à l'exception de Michel Desautels qui, l'année même de son élection en 1831, déclarait une terre de 30,6 hectares. Cependant, le lieutenant de milice Jean-Baptiste Beaudry, le plus important propriétaire foncier de cette paroisse ${ }^{83}$, a été élu une seule fois au conseil scolaire, en 1829.

81. Ces deux frères Blanchard dit Renaud sont les cousins par alliance du député Louis Raynault-Blanchard de Saint-Hyacinthe. Ce groupe familial composé principalement de cultivateurs aisés est fortement présent dans les diverses divisions de milice de la région du RichelieuYamaska. Voir C. Dessureault et R. Legault, «Les officiers de milice sédentaire du Bas-Canada: une étude exploratoire des réseaux familiaux", La rencontre de deux mondes : quête et conquête, Actes du xxvIII ${ }^{e}$ Congrès international des sciences généalogique et héraldique, Québec 2008, publication format pdf sur CD, La Société de généalogie de Québec.

82. BAnQ, notaire C. Têtu, le 9 juin 1829 et le 15 novembre 1829.

83. En 1831 , ce cultivateur possédait 285,6 hectares de terre dont 37,4 étaient défrichés. Une partie importante de ce patrimoine était alors situé dans le secteur du rang Saint-Dominique à Saint-Hyacinthe où le seigneur Dessaulles lui a concédé en 18266 terres d’une superficie totale 
À Saint-Damase, 8 cultivateurs accaparent 15 des 20 mandats de syndics scolaires. Le curé de la paroisse a été élu à deux reprises en 1829 et en 1830 et, la première année, il a vécu les mêmes péripéties que son collègue de Saint-Jean-Baptiste-de-Rouville. Le marchand Pierre-Claude Phaneuf, qui est aussi le plus important propriétaire foncier de cette localité en 1831, a été élu lors de la seconde élection de 1829, puis à deux reprises en 1830 et 1831. La dernière charge disponible a été occupée par Jean Maillet, de profession inconnue et apparemment sans propriété dans la paroisse en 1831. Ce dernier est toutefois le fils d'un marchand de Saint-Hyacinthe et il détenait le grade d'enseigne dans la milice.

Les syndics cultivateurs de Saint-Damase n'ont pas le même profil que ceux de la paroisse voisine de Saint-Jean-Baptiste. Nous n'avons pas retrouvé de liens familiaux au sein du groupe. De plus, la richesse foncière n'est pas un marqueur important puisque quatre des syndics cultivateurs de Saint-Damase possèdent des terres d'une superficie de 30,6 hectares ou moins et un de 43,2 hectares. Les deux plus importants propriétaires fonciers parmi ces syndics d'origine paysanne avaient des terres de 81,9 et de 75,5 hectares.

Par ailleurs, le nombre de mandats d'un individu n'est pas lié à l'importance de son patrimoine foncier. Certes, François Ayet, le deuxième plus important propriétaire foncier du groupe, a rempli trois mandats en 1829, 1830 et 1831 . Cependant, deux autres cultivateurs, dont les terres avaient 20,4 hectares, ont été élus à deux reprises et un autre, disposant d'une terre de 30,6 hectares, a été élu à quatre reprises. Ce dernier, Pierre Beaudry, était le plus ancien capitaine de milice de la paroisse et, conformément à ce titre, il présida les deux premières élections scolaires dans sa paroisse $^{84}$.

\section{LA PROPRIÉTÉ : UNE CONDITION ESSENTIELLE POUR ACCÉDER À LA CHARGE DE SYNDICS?}

Au Bas-Canada, le statut de propriétaire foncier est perçu, à tort ou à raison, comme l'un des gages de la capacité d'un citoyen à exercer ses droits de manière éclairée et indépendante des pressions extérieures. Les dirigeants coloniaux, de même que la plupart des hommes politiques

de 183,6 hectares. BAnQ, notaire J.-F. Têtu, le 27 juillet 1826. Au milieu des années 1830, ce cultivateur migre dans la nouvelle paroisse de Saint-Dominique où il accède au grade de capitaine dans la milice et devient l'un des premiers marguilliers de la fabrique paroissiale. AESH, I. Desnoyers, Histoire de la paroisse de Saint-Dominique, cahier manuscrit, vers 1880.

84. BAnQ, notaire C. Têtu, le 11 juin 1829 et le 15 juillet 1829 . 
conservateurs ou réformistes, souscrivent à cette conception. Le droit de voter et de se présenter à des élections est assujetti à la possession de biens fonciers. La participation active à la vie politique locale est aussi liée à la possession de biens fonciers comme le droit d'élire des syndics assumant la gestion de projets communautaires. La possession de biens fonciers constitue enfin un critère préférentiel dans l'accès à des charges publiques nominatives ${ }^{85}$.

Pourtant, même si la loi de 1829 exigeait que les syndics scolaires soient propriétaires dans leurs localités, nous avons 20 syndics de la première phase qui ont été explicitement identifiés comme n’étant pas propriétaires lors du recensement de $1831^{86}$. Ces derniers représentent environ $5 \%$ des 396 syndics de cette période pour lesquels nous disposons d'informations permettant de déterminer leur statut de propriétaire (voir le tableau 2). Ces syndics "sans propriété foncière » comptent d'abord 10 curés dont un seul a été élu avant la passation de l'amendement à la loi scolaire permettant à un membre du clergé d'être élu au conseil scolaire d'une localité sans y posséder de biens fonciers. Par ailleurs, la grande majorité des syndics laïques ne possédant pas d'emplacements ou de terres sont des notables $^{87}$. Ce groupe de notables compte un marchand, deux médecins, un notaire et deux bourgeois ${ }^{88}$. Nous avons aussi relevé parmi ces syndics "sans propriété foncière " un brasseur du village de Laprairie et un instituteur de Sainte-Scholastique ayant le même patronyme que le curé de cette paroisse. Ces syndics "sans terre» comptent enfin deux chefs de

85. Par exemple, en 1830, les députés de la Chambre d'assemblée adoptent une loi dans laquelle on précise de manière explicite des critères fondés sur la valeur de la propriété foncière d'un individu pour accéder à diverses charges d'officiers de milice. Acte pour pourvoir plus efficacement à la défense de la Province, et pour régler la Milice d'icelle, Lois de la province du Bas-Canada, 10, Geo. IV, ch. 3, 26 mars 1830.

86. En 1831, les recenseurs ont toutefois indiqué 0 à la rubrique sur le nombre d'arpents possédés pour 32 autres syndics de cette première phase qu'ils avaient pourtant identifiés comme étant propriétaires à une rubrique précédente du même recensement. Ce groupe comprend une majorité de notables dont deux hommes d'affaires influents du bourg de l'Assomption : le notaire Joseph-Édouard Faribault et le marchand Benjamin Beaupré. Ce groupe compte aussi deux cultivateurs dont Joseph Fortin, un capitaine de milice de la paroisse de Saint-Martin. En incluant ces individus, le pourcentage de syndics «sans propriété foncière " atteint 12\% (soit 52/428 cas plutôt que $20 / 396$ cas).

87. Parmi ces notables ruraux qui ne possédaient pas, à titre personnel, une propriété foncière d'après le recensement de 1831, nous pouvons mentionner le cas du marchand Thomas McVee de l'île-aux-Noix dans la seigneurie de Deléry. Ce dernier était alors lieutenant-colonel du Premier bataillon de la milice du comté de l'Acadie.

88. Ces deux bourgeois sont les fils des seigneurs Nicolas-Eustache Lambert-Dumont de Saint-Eustache et Ross Cuthbert de Lanoraie. 


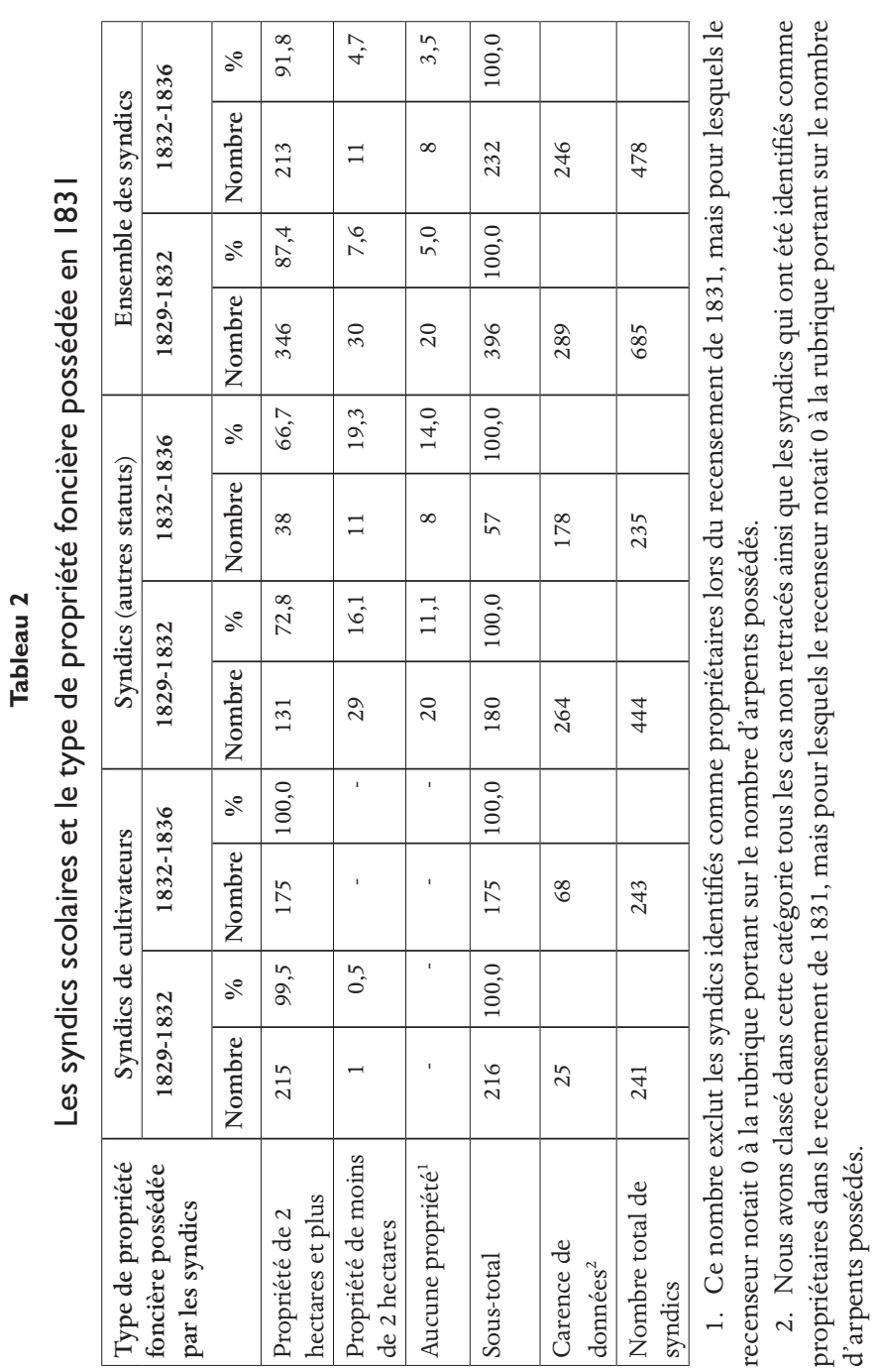

ménage explicitement identifiés comme donateur et rentier lors du recensement de 1831 dont un capitaine de milice, François Côté, qui a été élu à trois reprises à Saint-Charles-sur-Richelieu de 1829 à 1831. L'autre rentier est un lieutenant de milice qui a été élu en 1830 à Saint-Mathias-deRouville. Cette absence de propriété foncière ne semble pas liée à un statut social inférieur. Leur statut au sein de leur communauté respective a plutôt contribué à éviter des contestations électorales.

Dans la première phase des écoles de syndics, nous avons aussi relevé 30 propriétaires de lopins de moins de 2 hectares parmi les syndics sco- 
laires dont un seul cultivateur, demeurant dans un bourg, soit 7,6\% des 396 syndics élus pour lesquels nous avons des informations concernant la propriété foncière. Dans la seconde phase, à l'échelle des arrondissements, le pourcentage des syndics qui ont été identifiés comme n'étant pas propriétaires lors du recensement de 1831 descend à 3,5\% $\%^{89}$. Par ailleurs, le pourcentage des syndics possédant des lopins d'une superficie inférieure à deux hectares tombe sous les $5 \%$. Ces changements ne découlent pas d'une élévation des conditions requises pour accéder à la charge de syndics. Ils sont plutôt liés à un accroissement de la proportion des cultivateurs parmi l'ensemble des syndics. Nous n'avons aucun cultivateur parmi les syndics "sans propriété foncière ${ }^{90}$ ». Les propriétaires de lopins ou d'emplacements proviennent aussi de divers groupes socioprofessionnels à l'exception des cultivateurs.

\section{LA SUPERFICIE DES TERRES POSSÉDÉES PAR LES SYNDICS: UN INDICATEUR DU STATUT SOCIAL}

Plus de $98 \%$ des syndics cultivateurs et plus des deux tiers des autres syndics possèdent des terres d'une superficie de deux hectares et plus. L'étude fine de ces propriétés foncières permet d'affiner le portrait social des élus, surtout pour les syndics cultivateurs.

Dans la première phase des écoles des syndics, les superficies moyenne et médiane des terres de l'ensemble des syndics est de 73,4 et de 41 hectares (voir le tableau 3). Dans la seconde phase, cette superficie moyenne tombe à 53,6 hectares tandis que la superficie médiane demeure relativement stable, à 40,8 hectares. Cette évolution est en partie liée à la diminution de la proportion de syndics issus de la notabilité dans la seconde phase des écoles de syndics. La superficie moyenne des terres possédées par des syndics cultivateurs diminue aussi, mais moins fortement, de la première à la seconde phase des écoles de syndics. Cette superficie moyenne passe alors de 56,2 à 45,7 hectares tandis que la superficie médiane de leurs terres demeure plutôt stable autour de 41 hectares.

89. En 1831, les recenseurs ont toutefois indiqué 0 à la rubrique sur le nombre d'arpents possédés pour 14 autres syndics de cette seconde phase qu'ils avaient pourtant identifiés comme étant propriétaires à une rubrique précédente du même recensement. En incluant ces individus, le pourcentage de syndics «sans propriété foncière» atteint 8,9\% (soit 22/246 cas plutôt que 8/232 cas).

90. Nous avons trois syndics cultivateurs qui ont été identifiés par les recenseurs comme étant propriétaires en 1831, mais pour lesquels ces mêmes recenseurs ont indiqué 0 à la rubrique sur le nombre d'arpents possédés. 
Tableau 3

La superficie moyenne des propriétés foncières des syndics scolaires et des propriétaires de terres de deux hectares et plus dans 12 localités de la région de Montréal en 1831

\begin{tabular}{|c|c|c|c|c|c|c|}
\hline \multirow[t]{2}{*}{$\begin{array}{l}\text { Localité au recense- } \\
\text { ment de } 1831\end{array}$} & \multicolumn{3}{|c|}{$\begin{array}{l}\text { Tous les chefs de ménage } \\
\text { possédant } 2 \text { hectares et plus }\end{array}$} & \multicolumn{3}{|c|}{$\begin{array}{l}\text { Les cultivateurs possédant } \\
2 \text { hectares et plus }\end{array}$} \\
\hline & $\begin{array}{c}\text { Nombre } \\
\text { de cas }\end{array}$ & $\begin{array}{l}\text { Moyenne } \\
\text { (hectares) }\end{array}$ & $\begin{array}{c}\text { Médiane } \\
\text { (hectares) }\end{array}$ & $\begin{array}{c}\text { Nombre } \\
\text { de cas }\end{array}$ & $\begin{array}{l}\text { Moyenne } \\
\text { (hectares) }\end{array}$ & $\begin{array}{l}\text { Médiane } \\
\text { (hectares) }\end{array}$ \\
\hline Saint-Hyacinthe ${ }^{1}$ & 532 & 46,4 & 30,6 & 469 & 41,4 & 30,6 \\
\hline Saint-Césaire & 391 & 26,9 & 20,4 & 357 & 24,9 & 20,4 \\
\hline Saint-Denis & 227 & 45,1 & 30,6 & 202 & 39,7 & 30,6 \\
\hline Sorel $^{2}$ & 468 & 28,9 & 20,4 & 424 & 25,6 & 20,4 \\
\hline Monnoir & 616 & 30,8 & 28,9 & 573 & 29,9 & 20,4 \\
\hline Sabrevois & 173 & 32,3 & 19,0 & 160 & 32,8 & 19,0 \\
\hline Lanoraie & 144 & 37,7 & 29,4 & 122 & 39,4 & 30,6 \\
\hline Saint-Paul-de-Lavaltrie & 360 & 26,1 & 20,4 & 337 & 26,1 & 20,4 \\
\hline Saint-Vincent-de-Paul & 154 & 35,7 & 28,6 & 133 & 37,7 & 30,6 \\
\hline Saint-Martin & 243 & 27,1 & 24,3 & 213 & 29,4 & 27,2 \\
\hline Saint-Benoît & 505 & 30,3 & 30,5 & 439 & 29,2 & 30,6 \\
\hline Grenville & 195 & 50,1 & 41,0 & 164 & 50,5 & 41,0 \\
\hline Syndics scolaires phase 1 & 346 & 72,9 & 41,0 & 215 & 56,2 & 41,0 \\
\hline Syndics scolaires phase 2 & 213 & 53,6 & 40,8 & 175 & 45,7 & 40,8 \\
\hline
\end{tabular}

1. La localité de Saint-Hyacinthe comprend les deux subdivisions de la paroisse et du village de Saint-Hyacinthe.

2. La localité de Sorel comprend les deux subdivisions de la paroisse de Sorel et du bourg de William-Henry.

Que représentent ces superficies moyennes et médianes possédées par les syndics scolaires? Notre étude des syndics couvre plus d'une centaine de localités. Or, la structure foncière varie d'une localité à l'autre. Pour illustrer cette diversité et pour mieux saisir la portée de nos données sur la propriété foncière des syndics, nous avons calculé les superficies moyennes et médianes des terres dans 12 localités de la région de Montréal dont 6 sont situées dans 3 comtés de la rive sud du fleuve Saint-Laurent et 6 autres localités dans trois comtés de la rive nord. La superficie moyenne des terres possédées par les chefs de ménage de ces 12 localités varie de 26,1 à 50,1 hectares et la superficie médiane de 19 à 41 hectares $^{91}$.

91. Dans plusieurs localités, la superficie médiane des terres est de 20,4 ou 30,6 hectares, c'està-dire 60 ou 90 arpents. Dans la zone seigneuriale de la région de Montréal, la superficie initiale des terres concédées avait souvent ces dimensions. Dans le township de Grenville, la superficie médiane des terres est de 41 hectares et elle correspond aussi à la dimension initiale des terres concédées dans les cantons, soit 100 acres. 
Pour les cultivateurs, la superficie moyenne varie de 24,9 à 50,5 hectares et la superficie médiane de 19 à 41 hectares.

Dans la première phase des écoles de syndics, la superficie moyenne des terres de l'ensemble des syndics représente d'une fois et demie à près de trois fois la superficie moyenne des terres possédées par les chefs de ménage des différentes localités de notre échantillon. Par ailleurs, la superficie moyenne des terres des syndics cultivateurs est également supérieure à la superficie moyenne des terres possédées par l'ensemble des cultivateurs des localités retenues, mais seulement du simple au double. Dans la seconde phase des écoles de syndics, les syndics se démarquent moins des autres propriétaires fonciers de la région. Ainsi, la superficie moyenne de leurs terres représente désormais seulement d'une à deux fois la superficie moyenne des terres possédées par l'ensemble des chefs de ménage tandis que la superficie moyenne des terres des syndics cultivateurs est environ une fois et demie la superficie moyenne des terres possédées par l'ensemble des cultivateurs. Cette analyse des données foncières confirme aussi la plus importante sélectivité sociale des syndics durant la première phase, à l'échelle des localités, que dans la seconde phase, à l'échelle des arrondissements.

La répartition des syndics selon la superficie de la terre possédée permet de creuser cette question de la sélectivité de la charge. Nous constatons effectivement une sélection préférentielle des syndics selon la superficie des terres tant parmi les cultivateurs que parmi l'ensemble des propriétaires de deux hectares et plus. Cependant, la charge de syndics demeure ouverte aux différentes catégories de propriétaires fonciers (voir le tableau 4). Au bas de l'échelle, la catégorie de moins de 20 hectares qui constitue un peu plus du cinquième des propriétaires fonciers de la région (selon un échantillon de 12 paroisses) représente de 11 à $12 \%$ de tous les syndics propriétaires de 1829 à 1836 . La catégorie de 20 à 40 hectares, qui regroupe environ la moitié des propriétaires fonciers de la région, accapare $30 \%$ de l'ensemble des syndics propriétaires durant la première phase des écoles de syndics et cette proportion s'élève à $35 \%$ dans la seconde phase. La catégorie intermédiaire de 40 à 60 hectares constitue déjà, dans la plupart des localités de la région, une minorité assez bien nantie. Cette catégorie intermédiaire qui constitue environ $15 \%$ des propriétaires fonciers de la région augmente aussi sa présence dans les conseils scolaires de la première à la seconde phase, passant de moins de 23 à plus de $27 \%$.

Par contre, la proportion de syndics possédant des terres d'une superficie supérieure à 60 hectares passe d'environ du tiers au quart. Ces grands propriétaires représentent seulement $12 \%$ environ de l'ensemble des 
propriétaires fonciers de la région ainsi que des cultivateurs possédant des terres de deux hectares et plus. La baisse est encore plus importante pour la catégorie de 100 hectares et plus dont le pourcentage passe d'environ 15 à $5 \%$.

Cette réduction importante du nombre de grands propriétaires fonciers parmi les syndics scolaires est en partie liée au déclin de la présence des notables. Cependant, la proportion de grands propriétaires diminue aussi chez les syndics cultivateurs de la première à la seconde phase des écoles de syndics.

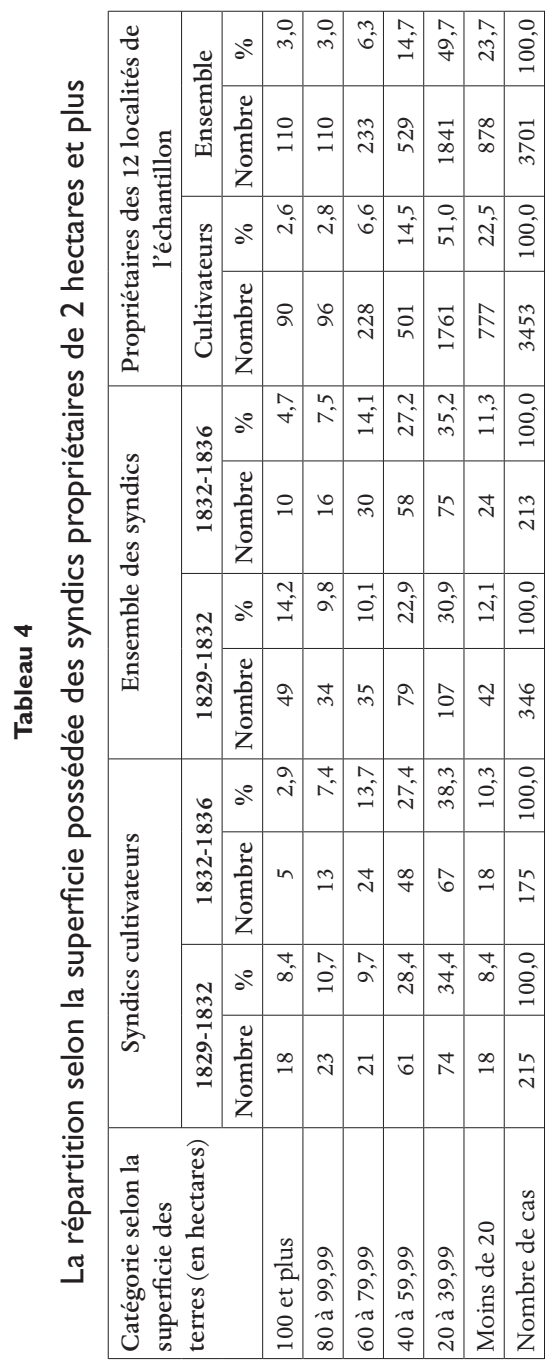




\section{LA PRÉSENCE DES OFFICIERS DE MILICE PARMI LES SYNDICS SCOLAIRES}

L'établissement des écoles de syndics commande le recrutement dans une même localité de cinq hommes désireux et capables, aux yeux de leurs concitoyens, d'assumer une nouvelle charge publique. La sélection de ces personnes ne s'effectue pas totalement au hasard. Le caractère des individus, de même que leur statut social, influence le choix parmi les candidats potentiels. La sélection des syndics scolaires devait sans doute s'appuyer également sur l'expérience des candidats. Certes, il n'y existe pas encore d'institutions municipales dans les campagnes bas-canadiennes. Mais les communautés locales disposent déjà d'un certain nombre d'institutions et de charges publiques électives et nominatives. L'appellation de syndics désigne d'ailleurs les détenteurs de charges publiques qui étaient élus par les propriétaires d'une même paroisse, d'un même bourg ou d'un même rang afin de superviser la réalisation d'un projet commun (construction ou réparation d'une église, d'un chemin ou d'un marché public ${ }^{92}$. Cependant, nous ne pouvons pas examiner l'ensemble des parcours de vie des syndics scolaires de la région de Montréal pour vérifier l'influence possible des expériences institutionnelles antérieures. Nous avons donc creusé cette question pour une institution spécifique: la milice.

Nous essayerons donc d'évaluer la présence des officiers de la milice sédentaire parmi les élus lors de la première phase des écoles de syndics de 1829 à 1832 . Nous avons ciblé cette période et cette institution, car nous disposons d'une banque de données assez complète avec le nom, le grade et le lieu de résidence des officiers de milice de l'ensemble des divisions de la milice sédentaire de la région de Montréal de 1829 à $1832^{93}$. Nous pouvons ainsi effectuer le jumelage des informations disponibles dans cette banque de données, dans les rapports électoraux des syndics et dans le recensement de 1831 .

Le choix de la milice repose aussi sur l'importance de cette institution dans la vie sociale des campagnes au Bas-Canada. La milice est d'abord une institution paramilitaire ${ }^{94}$. Pour les autorités coloniales, les miliciens

92. La loi scolaire de 1829 désigne donc les élus locaux sous le nom de syndics conformément à cette pratique traditionnelle, voir J.-P. Proulx, op. cit., 20-24.

93. Nous avons dépouillé et informatisé l'ensemble des listes d'officiers de milice disponibles pour la région de Montréal de 1790 à 1832 dans le cadre d'un projet de recherche sur la milice mené par Roch Legault, du Collège militaire royal de Kingston, et Christian Dessureault, de l’Université de Montréal.

94. La milice a une structure hiérarchique calquée sur le fonctionnement de l'armée avec divers grades permettant de distinguer, dans un ordre bien précis, les officiers d'un même bataillon ou d'une même division. De plus, les miliciens, de même que les officiers, doivent obéir aux ordres 
doivent contribuer à la défense du territoire lors de conflits éventuels. Cependant, les officiers de milice remplissent également des tâches administratives et policières au service de l'État et des communautés locales. Les officiers de milice servent en quelque sorte d'intermédiaires entre la société locale et l'État. Certes, c'est le gouverneur qui accorde officiellement les postes d'officiers dans la milice, de même que les promotions, à la suite d'une recommandation des commandants locaux. Cependant, la capacité d'un individu à remplir la charge d'officier de milice repose aussi en partie sur l'approbation et la confiance de ses concitoyens.

À l'instar des autorités coloniales, les députés du Parti patriote misent donc sur le prestige de la milice. La loi scolaire de 1829 confie ainsi l'organisation et la présidence de l'élection des syndics «au plus ancien officier de milice dans chaque Paroisse, Seigneurie ou Township ${ }^{95}$ ». La loi de 1832 permet ensuite à des juges de paix ou à des officiers de milice d'assumer ces mêmes responsabilités. Dans la région de Montréal, les officiers de milice, du capitaine au lieutenant-colonel, assument le plus souvent la présidence des élections scolaires. Cette loi confère par ailleurs de nouveaux pouvoirs potentiels aux officiers de milice. Le certificat de qualification des maîtres ou des maîtresses doit être signé par le curé ou le pasteur de la paroisse, de la seigneurie ou du canton où est située l'école ainsi que par le juge de paix ou l'officier de milice le plus en grade dans la localité. De plus, les officiers de milice sont expressément nommés parmi les personnes respectables qui peuvent accompagner les visiteurs lors de leur tournée d'inspection des écoles.

Les officiers de milice ont participé directement à la mise en œuvre de la nouvelle institution scolaire (voir le tableau 5). Ces derniers représentent $47,6 \%$ des laïques qui ont été élus à des conseils scolaires $(298 / 626)$ de la région de Montréal dans la première phase des écoles de syndics et ils détiennent 50,8\% des mandats remplis par des laïques (421/828). La sélectivité sociale de leur recrutement et le prestige lié au grade faisaient de ces officiers des candidats potentiels de premier plan. Ces derniers possédaient aussi une certaine expertise dans le commandement et la coordination des activités sociales.

La structure de la milice est fortement hiérarchisée. Les principaux postes de commandement dans la milice sont habituellement réservés

de leur supérieur. La crise politique récente sous Dalhousie a à la fois démontré les abus potentiels liés à cette conception et les limites de son champ d'application dans la société civile au BasCanada. Voir C. Dessureault, «La crise sous Dalhousie... », op. cit.

95. Acte pour encourager l'Éducation élémentaire, Lois de la province du Bas-Canada, 9, Geo. IV, ch. 46, 14 mars 1829. 
aux classes supérieures. La sélection des lieutenants-colonels et des majors s'effectue dans un ordre préférentiel parmi les seigneurs, les marchands et les professionnels. Le recrutement des officiers subalternes (capitaines, lieutenants et enseignes) est socialement plus diversifié. Ces officiers subalternes, surtout les capitaines, constituent une sorte d'élite intermédiaire composée de petits marchands, de professionnels et surtout de cultivateurs respectables, souvent un peu plus aisés et soudés entre eux par de multiples liens familiaux.

La représentation au sein des conseils scolaires des officiers de milice respecte cette hiérarchie de l'origine sociale et du rang dans la milice (voir le tableau 5). Les notables comptent une proportion beaucoup plus forte de syndics qui étaient déjà officiers dans la milice. Les syndics qui détenaient des grades supérieurs de lieutenant-colonel et de major proviennent principalement des milieux seigneuriaux et marchands. Les professions libérales et les bourgeois sont également présents dans ce groupe de syndics détenant des postes élevés dans la milice. Ces officiers supérieurs se font souvent élire à plus d'une reprise sur les conseils scolaires de leurs localités. Le seul syndic identifié à la fois comme cultivateur et comme lieutenant-colonel est Daniel De Hertel. Ce cultivateur est alors commandant de la division de milice d'Argenteuil ${ }^{96}$ et il siège à deux reprises en 1830 et en 1831 au conseil scolaire de la seigneurie du même nom. Ce cultivateur est le descendant du côté paternel d'une famille noble de la Nouvelle-France, et, du côté maternel, le petit-fils de Daniel Robertson, un officier militaire britannique qui a été, après sa retraite de l'armée, le premier commandant de la division de milice d'Argenteuil.

La charge de chirurgien est un cas à part dans la milice puisqu'il est réservé à des médecins et, au niveau des grades, il équivaut au rang de capitaine. La fréquence de leur élection comme syndic se situe dans la moyenne. Parmi les officiers de milice subalternes, les capitaines fournissent le plus grand nombre de syndics scolaires et la fréquence de leur élection sur des conseils scolaires est plus élevée que la moyenne. Ils adoptent à ce sujet un comportement proche des notables. Ces syndics qui assumaient dans leur milieu le rôle de capitaine de milice proviennent de divers horizons socioprofessionnels. Cependant, les cultivateurs en constituent le noyau principal. Plus bas dans l'échelle de la milice, les lieutenants et les enseignes sont également nombreux à investir la

96. C. Dessureault et R. Legault, «Les voies d'accès au commandement de la milice de la région de Montréal au Bas-Canada (1790-1839)", dans R. Legault, dir., Le leadership militaire canadien-français. Continuité, efficacité et loyauté (Kingston/Toronto, Presse de l'Académie canadienne de la défense/The Dundurn Group, 2007), 91-129. 


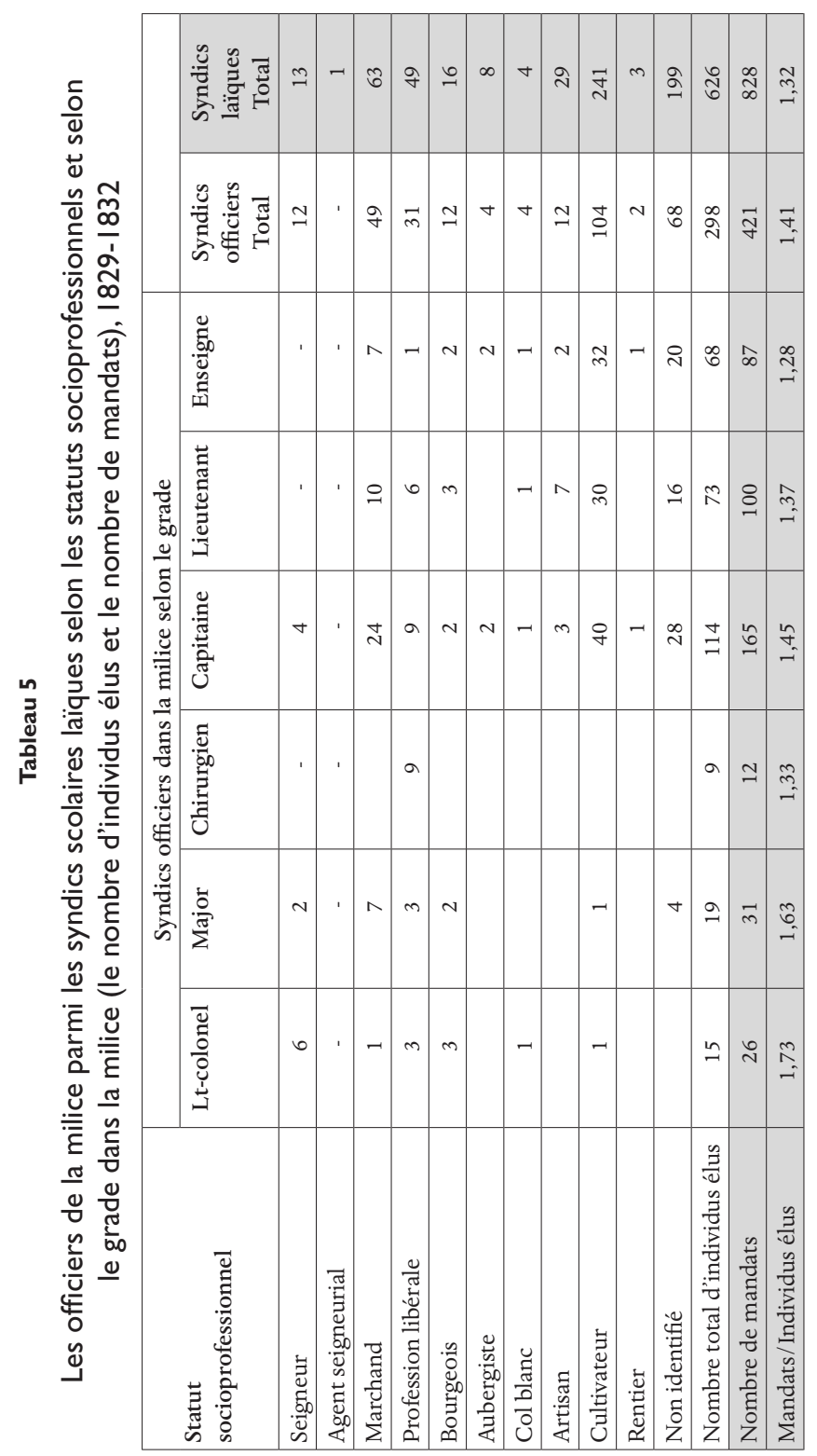

nouvelle institution scolaire. Leur participation décline toutefois selon l'importance du grade.

L'indicateur foncier révèle la dimension élitaire des syndics issus de la milice. La superficie moyenne des terres possédées par les officiers qui ont siégé à des conseils scolaires entre 1829 et 1832 est de 92 hectares (160 cas). 
Pour les syndics cultivateurs issus de la milice, la superficie moyenne de leurs terres est de 69,6 hectares (88 cas). Parmi les cultivateurs, cette superficie moyenne évolue selon le grade à l'exception du lieutenantcolonel De Hertel qui possédait une terre de 30,6 hectares dans la seigneurie d'Argenteuil. La propriété du major Jean-Baptiste Demers, cultivateur à Saint-Mathias-de-Rouville, est de 136,7 hectares tandis que les superficies moyennes des terres des autres syndics cultivateurs actifs dans la milice sont respectivement de 85,3 hectares pour les capitaines ( 33 cas), de 60,1 hectares pour les lieutenants ( 25 cas) et de 58,6 hectares pour les enseignes (28 cas). Les officiers supérieurs et les capitaines qui étaient invités à présider les élections dans leurs localités étaient souvent euxmêmes élus au nouveau conseil scolaire.

Nous avons relevé seulement trois localités n'ayant aucun officier de la milice dans les conseils scolaires entre 1829 et 1832 (carte 5). Ce sont trois paroisses rurales de l'ouest de l'île de Montréal. Par ailleurs, cinq autres localités dont quatre sont situées dans des secteurs de peuplement récent, à la périphérie de la plaine de Montréal, ont élu un seul officier pour deux élections scolaires ou plus. Les autres localités de la région ont au moins élu un officier de milice lors de chacune des élections scolaires et la majorité en

\section{Carte 5}

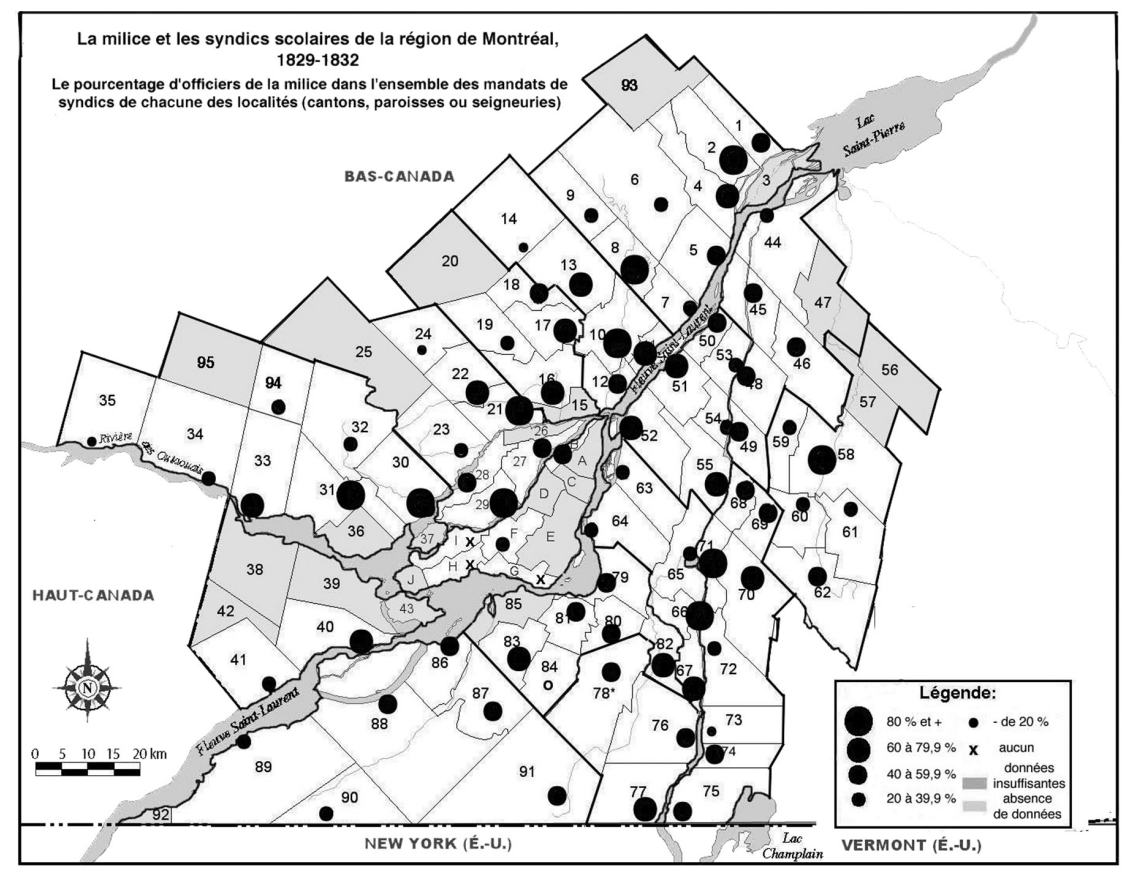


ont élu au moins deux par élection. Les localités comptant plusieurs notables parmi les syndics scolaires sont souvent celles qui ont le plus grand nombre d'officiers de milice sur leurs conseils scolaires puisque plusieurs notables détiennent des postes de commandement dans cette institution. Cependant, la présence des officiers de milice dans les conseils scolaires est à la fois plus large et plus dense que celle des notables.

\section{LA PARTICIPATION ANGLOPHONE À LA NOUVELLE INSTITUTION SCOLAIRE}

La création des écoles de syndics résulte de l'initiative de députés du Parti patriote. La mise en place de ce système scolaire visait à répondre aux besoins particuliers de la population rurale catholique d'origine française. L'attrait envers la nouvelle institution qui confie à des syndics élus localement la gestion des écoles élémentaires est toutefois important au sein de la population rurale d'origine américaine et britannique, majoritairement protestante. Nous avons essayé, à partir de la consonance des noms et des prénoms des syndics ${ }^{97}$, d'évaluer la présence de ces groupes minoritaires parmi les syndics scolaires élus dans la région de Montréal. Nous sommes conscient des lacunes de cette démarche, mais nous croyons qu'elle permet au moins de déterminer un ordre de grandeur de cette participation et d'en révéler certains traits particuliers.

Pour la première phase des écoles de syndics, de 1829 à 1832, nous avons ainsi identifié 215 syndics appartenant vraisemblablement aux groupes américano-britanniques soit environ $31,5 \%$ des 625 syndics de la période. Ces derniers ont cumulé $28 \%$ des 921 charges, soit 258 . Nous pouvons répartir ces syndics en trois sous-groupes.

Le premier sous-groupe de syndics anglophones compte 142 individus résidant dans 17 localités ou parties de localités (cantons, paroisses et seigneuries) principalement peuplées de colons d'origine américaine ou britannique, incluant le bourg de William Henry dans la localité de Sorel98.

97. Dans un article sur l'évolution de la ville de Québec au xviII siècle, Louise Dechêne a effectué une critique radicale de ce type de démarche. Nous ne souscrivons pas totalement à son point de vue. En l'absence de sources totalement adéquates, l'historien doit quelquefois emprunter des chemins moins balisés sinon il devrait laisser dans l'ombre certaines dimensions importantes de la réalité du passé. Toutefois, il doit demeurer conscient des carences méthodologiques de la démarche suivie et de la marge d'erreur qui en découle. Par ailleurs, nous avons utilisé notre connaissance acquise des milieux étudiés pour effectuer au mieux l'identification des syndics anglophones. Voir L. Dechêne, "Quelques aspects de la ville de Québec d'après les dénombrements paroissiaux», Cahiers de géographie de Québec, 28,75 (1984) : 485-505.

98. Ces localités ou parties de localités sont le bourg de William Henry, les paroisses protestantes de New Glascow et de St-Paul d'Abbotsford; les seigneuries d'Argenteuil, Lacolle, Noyan, 
Ces 142 syndics ont accaparé 161 des 165 charges de syndics disponibles lors des élections scolaires tenues dans ces localités ou parties de localités ${ }^{99}$. Leur recrutement s'est surtout effectué parmi les cultivateurs. Ces derniers représentent plus de $75 \%$ des syndics dont nous avons réussi à identifier la profession (69/91). Nous avons aussi relevé un maître d'école, un huissier et trois artisans. Par contre, nous avons identifié seulement dix-sept notables dans ce sous-groupe anglophone incluant six pasteurs, un agent seigneurial et deux bourgeois. Le bourg de William Henry a élu sept de ces 17 notables.

Le second sous-groupe de syndics anglophones compte 43 individus qui ont été élus dans dix localités de la région de Montréal comptant une minorité importante ou une légère majorité d'Anglophones. Ces derniers ont détenu dans ces localités 53 des 100 charges électives. Ces autres syndics anglophones sont principalement des cultivateurs qui constituent $84 \%$ de tous ceux dont nous avons identifié le statut ou la profession $(21 / 25)$. Nous avons retracé dans ce sous-groupe seulement trois notables dont deux marchands et un révérend. Dans cinq de ces dix localités, les Anglophones ont occupé la majorité des sièges disponibles aux conseils scolaires lors d'une ou de deux élections: dans les paroisses de Saint-Lin ( $\mathrm{n}^{\circ}$ 19) et de Saint-Rémi-de-Lasalle ( ${ }^{\circ} 84$ ), dans les seigneuries de la Nouvelle-Longueuil ( $\left.\mathrm{n}^{\circ} 41\right)$, de Deléry $\left(\mathrm{n}^{\circ} 76\right)$ et de Sabrevois $\left(\mathrm{n}^{\circ} 73\right)$. Cette cohabitation pourtant peu fréquente de syndics anglophones, souvent protestants, et de syndics francophones effraie et choque l'évêque auxiliaire de Montréal, $\mathrm{M}^{\mathrm{gr}}$ Lartigue: «Je connais déjà des paroisses catholiques où sur cinq syndics appointés pour une école basée d'après le nouveau bill (1829), trois protestants ont trouvé le tour de se faire nommer et les deux catholiques sans éducation sont incapables de leur faire face ${ }^{100}$.»

Le dernier sous-groupe de syndics anglophones compte 30 individus élus dans des localités majoritairement peuplées de Canadiens d’origine

Ramesay et St-James; ainsi que les cantons de Chatham, Godmanchester, Gore, Grenville, Hemmingford, Hinchinbrooke, Kildare, Rawdon et Sherrington. Le cas de William Henry est un cas particulier, car il regroupe dans un conseil distinct les anglo-protestants de la paroisse de Sorel qui, dans son ensemble, est peuplée majoritairement de franco-catholiques.

99. Les quatre syndics francophones ont été élus dans la seigneurie de Ramsesay (1 charge sur 5), dans la seigneurie de Noyan (1 charge sur 10) et dans le canton de Godmanchester ( 2 charges sur 10 occupées par un même individu, le capitaine Antoine Dupuis). Nous pourrions aussi inclure les deux charges occupées par le lieutenant-colonel de milice Daniel De Hertel qui a été élu en 1830 et en 1831 dans la seigneurie d'Argenteuil. Ce dernier était à la fois d'origine britannique, par sa mère, et française, par son père.

100. Archives de l'Archevêché de Montréal, Registre des lettres, v. 5, 191: Lettre de $\mathrm{M}^{\mathrm{gr}}$ Lartigue à MM. Hébert, Bilodeau, Mode et Dorion de Saint-Ours, le 23 décembre 1829, cité dans L.-P. Audet, op. cit., 135. 
française. Le profil social de ces syndics est fort différent. Les notables, en incluant quatre bourgeois, représentent les deux tiers des syndics de ce sous-groupe anglophone dont nous avons identifié le statut socioprofessionnel (14/21), et les cultivateurs moins de $10 \%(2 / 21)$. Ces notables sont souvent des personnages influents dans leurs localités respectives tel le conseiller législatif Roderick McKenzie à Terrebonne ou le marchand William U. Chaffers à Saint-Césaire ${ }^{101}$.

Pour la seconde phase des écoles de syndics, nous avons réussi à identifier seulement 74 Anglophones parmi les 478 syndics de cette période, soit $15,5 \%$. Ces derniers ont cumulé $16 \%$ des charges (84/525). Cependant, ce recul considérable de la proportion de syndics identifiés dans les sources ne correspond pas nécessairement à une diminution réelle du nombre d'écoles de syndics dans les localités concernées ${ }^{102}$. Comme nous l'avons déjà souligné dans la section méthodologique, les procès-verbaux électoraux déposés chez les notaires, la source exclusive employée pour cette seconde phase des écoles de syndics permet d'identifier une proportion relativement faible des syndics dans la plupart des secteurs de la région ${ }^{103}$. L'emploi de la source notariale entraîne à l'évidence une sous-évaluation de la proportion de syndics anglophones même si de nombreuses localités francophones n’ont également laissé aucune trace dans les archives notariales des élections scolaires tenues durant cette période. Nous avons d'ailleurs retracé seulement 18 syndics élus, une seule fois chacun, dans des milieux majoritairement anglophones. Ce sont presque essentiellement des cultivateurs. Nous avons par ailleurs relevé 45 syndics anglophones élus dans des paroisses mixtes et ces derniers cumulent 56 charges. Tous les syndics de ce sousgroupe dont nous avons identifié la profession proviennent aussi des classes populaires dont 20 cultivateurs et 1 artisan. Enfin, lors de cette seconde phase, dix autres syndics anglophones ont été élus dans des paroisses majoritairement francophones dont cinq sont des marchands.

101. William U. Chaffers a été élu à trois reprises au conseil scolaire de la paroisse de SaintCésaire en 1829, 1830 et 1831 . Cette paroisse compte à cette époque une petite communauté anglophone dans le secteur de la montagne de Rougemont, Cependant, W. U. Chaffers n'est pas vraiment un membre de cette communauté. Ce marchand réside au village de Saint-Césaire au milieu de la communauté francophone majoritaire. Ce dernier est par ailleurs le gendre du docteur François Blanchet de Québec, l'un des députés patriotes à l'origine du projet de loi de 1829. Ce marchand, major dans la milice et juge de paix, est toutefois un adversaire des patriotes lors des Rébellions de 1837-1838.

102. Les données des rapports publiés ne permettent malheureusement pas de suivre le nombre d'écoles par localité, mais seulement par comté. De plus, ils ne précisent pas toujours si ces écoles sont des écoles de syndics, des écoles de fabrique ou des écoles de l'institution royale.

103. Voir infra, la section méthodologique et le carte 3. 
Durant la première phase des écoles de syndics, le choix des représentants scolaires dans les milieux ruraux anglophones est un peu moins sélectif que dans les milieux francophones, à l'exception du bourg de William Henry enclavé dans une paroisse majoritairement francophone. Ces milieux ruraux sont principalement situés dans des secteurs de peuplement récent, à la périphérie de la plaine de Montréal. Les indicateurs fonciers pointent dans la même direction que les statuts socioprofessionnels. Dans la première phase des écoles de syndics, la superficie moyenne des terres de l'ensemble des syndics anglophones, incluant les notables élus dans des paroisses majoritairement francophones, est légèrement plus faible que chez les syndics francophones et le même phénomène se vérifie chez les syndics cultivateurs, alors que la superficie des terres est généralement plus grande dans les cantons (voir le tableau 6).

Tableau 6

La superficie moyenne comparée des terres possédées par les syndics anglophones et francophones dans la première phase des écoles de syndics, 1829-1832 (terres de 2 hectares et plus)

\begin{tabular}{|l|c|c|c|c|}
\hline \multirow{2}{*}{ Groupe } & \multicolumn{2}{|c|}{$\begin{array}{c}\text { Ensemble des syndics } \\
\text { Superficie des terres }\end{array}$} & \multicolumn{2}{c|}{$\begin{array}{c}\text { Syndics cultivateurs } \\
\text { Superficie des terres }\end{array}$} \\
\cline { 2 - 5 } & $\begin{array}{c}\text { Nombre } \\
\text { de cas }\end{array}$ & $\begin{array}{c}\text { Moyenne } \\
\text { (hectares) }\end{array}$ & $\begin{array}{c}\text { Nombre } \\
\text { de cas }\end{array}$ & $\begin{array}{c}\text { Moyenne } \\
\text { (hectares) }\end{array}$ \\
\hline Anglophones & 116 & 68,2 & 89 & 54,6 \\
\hline Francophones & 230 & 75,3 & 126 & 57,4 \\
\hline Total & 346 & 72,9 & 215 & 56,2 \\
\hline
\end{tabular}

Les officiers de milice sont également moins présents parmi les syndics anglophones. Nous avons identifié $32 \%$ d'officiers de milice parmi les syndics anglophones $(69 / 215)$ et ils ont rempli environ $36 \%$ des charges détenues par des Anglophones sur les conseils scolaires en excluant les charges occupées par des membres du clergé (89 sur 248). Cette présence des officiers de milice sur les conseils scolaires est encore plus faible dans les localités majoritairement peuplées d'Anglophones où nous avons retrouvé moins de $28 \%$ d'officiers parmi les syndics scolaires en excluant les membres du clergé (39/142).

\section{CONCLUSION}

Le principe électif proposé dans la loi de 1829 visait-il à étendre le pouvoir des élites laïques liées au Parti patriote? Nous ne pouvons pas, à partir de cette étude du profil social des syndics, appréhender les intentions secrètes 
des législateurs. Nous pouvons toutefois évaluer la participation des divers groupes socioprofessionnels aux conseils scolaires.

Dans la première phase des écoles de syndics, les notables laïques occupent sur les conseils scolaires une place plus grande que leur poids démographique. Ces derniers détiennent le contrôle des conseils dans la plupart des localités dotées d'un bourg important. Mais le principe électif n’a pas rebuté les curés de campagne et il n'a pas servi à évincer les opposants du Parti patriote. Les cultivateurs sont aussi très fortement présents parmi les élus de la première phase des écoles de syndics et, dans plusieurs localités, leur poids était même déterminant. La sélection s'effectue principalement parmi les cultivateurs dont la superficie des terres varie entre 20 à 60 hectares. Cependant, ce groupe compte aussi plusieurs gros propriétaires fonciers. Enfin, la présence dans les conseils scolaires de nombreux officiers de milice, tant des cultivateurs que des notables, renforce la dimension élitaire de la nouvelle institution scolaire dans la première phase des écoles de syndics entre 1829 et 1832 . Les écoles de syndics ont alors suscité l'enthousiasme des élites locales surtout dans les localités majoritairement francophones. Cependant, elle demeure une institution ouverte à la plupart des ruraux à l'exception des journaliers et des fermiers (cultivateurs sans terre exploitant la terre d'un tiers). En 1832, l'adoption des arrondissements comme unité de base de la nouvelle démocratie scolaire a des répercussions importantes sur le profil social des syndics. Elle entraîne un déclin de la présence des notables et le renforcement de la place des cultivateurs possédant entre 20 et 60 hectares.

Dans cet article, nous avons défini la notabilité principalement à partir de l'appartenance à certains groupes socioprofessionnels. Pourtant, certains travaux récents ont montré la nécessité de dépasser cette définition étroite de la notabilité. Certains cultivateurs sont dans leur milieu des membres à part entière de l'élite locale. Ils remplissent des rôles importants dans l'organisation de la vie politique locale et représentent, à leur manière, des intermédiaires entre la société locale et le monde extérieur. Cependant, tous les acteurs n'occupent pas des places équivalentes dans la hiérarchie sociale. Certes, il faudrait davantage que les indicateurs de la profession ou de la richesse foncière pour déterminer la place des uns et des autres dans la hiérarchie sociale. Cette sociographie des syndics scolaires contribue néanmoins à éclairer la nature composite de l'élite rurale et la prédominance des notables dans les principales localités rurales de la région de Montréal où des bourgs constituent des centres importants de pouvoir. 
Annexe I

\section{Listes des unités territoriales des cartes}

\begin{tabular}{|c|c|}
\hline 1. Saint-Barthelémy & 48. Saint-Denis \\
\hline 2. Saint-Cuthbert & 49. Saint-Charles \\
\hline 3. Île-Dupas & 50. Contrecoeur \\
\hline 4. Berthier & 51. Verchères \\
\hline 5. Lanoraie & 52. Varennes \\
\hline 6. Sainte-Élizabeth & 53. Saint-Antoine (Richelieu) \\
\hline 7. Saint-Antoine-de-Lavaltrie & 54. Saint-Marc \\
\hline 8. Saint-Paul-de-Lavaltrie & 55. Belœil \\
\hline 9. Kildare & 56. Saint-Hugues \\
\hline 10. L'Assomption & 57. Saint-Simon \\
\hline 11. Saint-Sulpice & 58. Saint-Hyacinthe \\
\hline 12. Repentigny & 59. La Présentation \\
\hline 13. Saint-Jacques-l'Achigan & 60. Saint-Damase \\
\hline 14. Rawdon & 61. Saint-Pie \\
\hline 15. Lachenaie & 62. Saint-Césaire \\
\hline 16. Mascouche & 63. Boucherville \\
\hline 17. Saint-Roch-l'Achigan & 64. Longueuil \\
\hline 18. Saint-Esprit & 65. Chambly \\
\hline 19. Saint-Lin & 66. Saint-Luc \\
\hline 20. Kilkenny & 67. Saint-Jean \\
\hline 21. Terrebonne & 68. Saint-Hilaire \\
\hline 22. Sainte-Anne-des-Plaines & 69. Saint-Jean-Baptiste-de-Rouville \\
\hline 23. Sainte-Thérèse & 70. Sainte-Marie-de-Monnoir \\
\hline 24. New Glasgow & 71. Saint-Mathias \\
\hline 25. Rivière-du-Nord & 72. Saint-Athanase \\
\hline 26. Saint-François-de-Sales & 73. Sabrevois \\
\hline 27. Saint-Vincent-de-Paul & 74. Noyan \\
\hline 28. Saint-Martin & 75. Foucault \\
\hline 29. Sainte-Rose & 76. Deléry \\
\hline 30. Saint-Eustache & 77. Lacolle \\
\hline 31. Saint-Benoît & 78. Saint-Édouard* \\
\hline 32. Sainte-Scholastique & 79. Laprairie \\
\hline 33. Argenteuil & 80. Saint-Philippe \\
\hline 34. Chatam & 81. Saint-Constant \\
\hline 35. Grenville & 82. Sainte-Marguerite-de-Blairfindie \\
\hline 36. La Mission du Lac (Oka) & 83. Saint-Joachim \\
\hline 37. Île-Bizard & 84. Saint-Rémi-de-Lasalle \\
\hline 38. Rigaud & 85. Sault-Saint-Louis \\
\hline 39. Vaudreuil & 86. Saint-Clément \\
\hline 40. Soulanges & 87. Sainte-Martine ${ }^{\star}$ \\
\hline 41. Nouvelle-Longueuil & 88. Saint-Thimothée \\
\hline 42. Newton & 89. Godmanchester \\
\hline 43. Île-Perrôt & 90. Hinchinbrooke \\
\hline 44. Sorel & 91. Hemmingford \\
\hline 45. Saint-Ours & 92. Mission de Saint-Régis \\
\hline 46. Saint-Judes & 93. Lac Maskinongé \\
\hline 47. Barrow ${ }^{\star}$ & 94. Gore \\
\hline
\end{tabular}


95. Wenntworth

A. Pointe-aux-Trembles

B. Rivière-des-Prairies

C. Longue-Pointe

D. Sault-au-Récollet

E. Notre-Dame (zone rurale)
F. Saint-Laurent

G. Lachine

H. Pointe-Claire

I. Sainte-Geneviève

J. Sainte-Anne-de-l'île-de-Montréal

Définition: Les unités territoriales numérotées correspondent aux subdivisions de recensement dans chacun des comtés en 1831. Ces subdivisions réfèrent le plus souvent à des paroisses, mais elles peuvent aussi représenter des cantons ou des seigneuries.

47^. L’unité Barrow couvre les fiefs de Bourgmarie-Ouest, de Bonsecours et de Saint-Charles dont Thomas Barrow est le seigneur en 1831.

$78^{\star}$. L'unité Saint-Édouard est le nom d'une paroisse qui, en 1831, couvre les fiefs de Saint-Georges, de Saint-Normand et de Thwaite ainsi que le canton de Sherrington.

$87^{\star}$. Cette unité comprend la paroisse de Sainte-Martine ainsi que les secteurs de Georgetown, Jamestown, Ormstown et Russeltown. 


\section{Annexe 2}

\section{Notes sur les données des 12 localités témoins}

Nous avons voulu déterminer à partir d'un échantillon de localités (cantons, paroisses et seigneuries) la répartition des statuts socioprofessionnels et la taille des propriétés foncières des chefs de ménage de la région de Montréal au recensement de 1831 afin de situer les données concernant les syndics scolaires. Nous sommes conscients que les résultats obtenus à partir de cet échantillon constituent seulement des ordres de grandeur par rapport à des données à l'échelle de la région. Nous avons procédé à partir d’un échantillon de localités compte tenu du volume considérable d'informations à traiter et surtout de l'absence d'uniformité dans le travail des recenseurs d'une localité à l'autre, principalement en ce qui concerne l'enregistrement des statuts et des professions. Nous avons sélectionné six localités de trois comtés de la rive sud et six localités de trois comtés de la rive nord du Saint-Laurent. Ces localités sont Sorel et Saint-Denis dans le comté de Richelieu; Saint-Hyacinthe et SaintCésaire dans le comté de Saint-Hyacinthe; Monnoir et Deléry dans le comté de Rouville; Lanoraie et Saint-Paul-de-Lavaltrie dans le comté de Berthier; Saint-Vincent-de-Paul et SaintMartin dans le comté de Terrebonne; et enfin Saint-Benoît et le township de Grenville dans le comté de Deux-Montagnes.

Nous voulions d'abord un échantillon de localités assez large et bien réparti dans l'espace régional comprenant à la fois des terroirs anciennement peuplés et des secteurs plus récemment occupés. Nous avons aussi tenu compte de la qualité apparente du travail des recenseurs dans le choix final des localités. Malgré cela, nous devons souligner des variations dans le travail des recenseurs d'une localité à l'autre, dont voici quelques exemples. Le terme de bourgeois pour qualifier le statut d'un chef de ménage est employé plus fréquemment dans certaines localités et n’a donc pas toujours la même sélectivité sociale. Ainsi, 22 des 873 chefs de ménage de la paroisse de Sainte-Marie-de-Monnoir sont identifiés comme bourgeois contre un seul des 864 chefs de ménage de la paroisse de Saint-Hyacinthe. Nous avons par ailleurs classé dans la catégorie des bourgeois 12 chefs de ménage anglophones de Sorel que le recenseur identifiait comme gentleman. Les recenseurs n'ont pas distingué de manière systématique, dans toutes les paroisses, les donateurs ou les rentiers des cultivateurs actifs. À SaintMartin, le terme de cultivateur est employé autant pour désigner les chefs de ménage actifs que les chefs de ménage à la retraite. À Saint-Hyacinthe, le recenseur relève seulement trois rentiers pour 864 chefs de ménage tandis la paroisse de Saint-Césaire, de peuplement récent, compte 14 rentiers pour 504 chefs de ménage.

Nous avons par ailleurs classé parmi les rentiers 14 chefs de ménage identifié à Sorel (William Henry) comme «invalides». Ces «invalides» sont vraisemblablement de vieux réfugiés «loyalistes » bénéficiant d’une pension du gouvernement colonial pour assurer leur subsistance. Dans certaines localités, le recenseur utilise le terme de cultivateur pour désigner l'ensemble des exploitants agricoles tandis que dans d'autres ce terme est réservé aux chefs de ménage qui sont propriétaires de leur exploitation. Dans ces autres paroisses, le terme de fermiers sert alors à identifier les chefs de ménage agricoles qui cultivent la terre appartenant à un tiers. Nous avons intégré ces chefs de ménage agricoles dans une seule et même catégorie malgré la distinction sociale évidente entre les deux groupes. Dans la paroisse de Saint-Denis où le recenseur distingue nettement les fermiers des autres cultivateurs, ces derniers regroupent 56 des 261 chefs de ménage agricoles de la localité, soit $21,5 \%$.

Le relevé des professions ou des statuts des femmes chefs de ménage est également très inégal d'une paroisse à l'autre. Les paroisses de Saint-Hyacinthe et de Saint-Martin compte respectivement 17 et 4 veuves sans profession ou statut tandis dans les autres paroisses de notre échantillon, les recenseurs notent pour chacune des veuves un statut social ou un métier: bourgeoise, marchande, couturière, cultivatrice, journalière ou tisserande. Nous pourrions relever d'autres variations dans le travail des recenseurs, mais celles-ci ont finalement un impact relativement mineur. 